\title{
Clinical Pharmacokinetics of the Novel HIV-1 Non-Nucleoside Reverse Transcriptase Inhibitor Doravirine: An Assessment of the Effect of Patient Characteristics and Drug-Drug Interactions
}

\author{
Sauzanne Khalilieh ${ }^{1}\left(\mathbb{0} \cdot \mathrm{Ka}_{\text {Lai Yee }}^{2}\left(\mathbb{D} \cdot\right.\right.$ Rosa Sanchez $^{2} \cdot$ S. Aubrey Stoch ${ }^{2} \cdot$ Larissa Wenning $^{2} \cdot$ Marian Iwamoto $^{2}$
}

Published online: 20 August 2020

(c) The Author(s) 2020

\begin{abstract}
Doravirine (MK-1439) is a novel non-nucleoside reverse transcriptase inhibitor indicated for the combination treatment of human immunodeficiency virus type-1 (HIV-1) infection. The recommended dose is $100 \mathrm{mg}$ once daily. This review summarizes the pharmacokinetics of doravirine, the influence of intrinsic factors, and its drug-drug interaction (DDI) profile. Following oral administration, doravirine is rapidly absorbed (median time to maximum plasma concentration, $1-4 \mathrm{~h}$ ) and undergoes cytochrome P450 (CYP)3A-mediated oxidative metabolism. Steady-state geometric means for AUC $0-24, C_{24}$, and $C_{\max }$ in individuals with HIV-1 following administration of doravirine $100 \mathrm{mg}$ once daily are $37.8 \mu \mathrm{M} \cdot \mathrm{h}, 930 \mathrm{nM}$, and $2260 \mathrm{nM}$, respectively. Age, gender, severe renal impairment, and moderate hepatic impairment have no clinically meaningful effect on doravirine pharmacokinetics, and there is limited potential for DDIs. No dose adjustment is necessary when doravirine is co-administered with strong CYP3A inhibitors. However, doravirine is contraindicated with strong CYP3A inducers (e.g., rifampin), and dose adjustment of doravirine is recommended for co-administration with the moderate CYP3A inducer, rifabutin. Included in this review are clinical trial data from phase I pharmacokinetic trials, including DDI trials and trials in participants with renal and hepatic disease but without HIV-1 infection $(N=326)$, as well as phase I, II, and III safety and efficacy trials in participants living with HIV-1 $(N=991)$. Based on these data, the pharmacokinetic profile of doravirine supports its use in diverse populations living with HIV-1 and allows co-administration with various antiretroviral agents and treatments for commonly occurring co-morbidities.
\end{abstract}

\section{Introduction}

Human immunodeficiency virus (HIV) infection continues to be a global concern. In 2017, nearly 37 million people worldwide were living with HIV, and 1.8 million people were newly diagnosed with the virus [1]. Current guidelines recommend that all individuals with HIV infection be treated with antiretroviral therapy [2, 3]. First-line threedrug regimens generally consist of two nucleoside reverse

Electronic supplementary material The online version of this article (https://doi.org/10.1007/s40261-020-00934-2) contains supplementary material, which is available to authorized users.

Sauzanne Khalilieh and Ka Lai Yee contributed equally.

Sauzanne Khalilieh

sauzanne.khalilieh@merck.com

1 Merck \& Co., Inc., Galloping Hill Road, Kenilworth, NJ 07033, USA

2 Merck \& Co., Inc., Kenilworth, NJ, USA transcriptase inhibitors (NRTIs) in combination with a third drug from another class, usually an integrase strand transfer inhibitor (InSTI) for most individuals with HIV initiating antiretroviral therapy; a non-nucleoside reverse transcriptase inhibitor (NNRTI) or a boosted protease inhibitor (PI) may be given instead of an InSTI in certain clinical situations [2, 3]. Although many treatment options are available, multiple factors can reduce the appropriateness of certain therapies for some individuals, including viral resistance to antiretroviral drugs, tolerability and associated side effects, and drug-drug interactions (DDIs). Among NNRTIs, efavirenz has been associated with central nervous system-related adverse events (AEs) as well as significant DDIs, and rilpivirine has reduced efficacy in individuals with high baseline HIV RNA and a low $\mathrm{CD}^{+}$cell count [3].

Doravirine is a novel NNRTI designed to overcome the limitations of other drugs in the class [4,5]. Doravirine is active in vitro against typical NNRTI-associated mutations that are susceptible to other NNRTIs and exhibits a low rate of resistance and a unique resistance pathway $[6,7]$. In two 


\section{Key Points}

There is limited potential for demographics and organ impairment to affect the pharmacokinetics of doravirine.

There is limited potential for drug-drug interactions with doravirine; however, co-administration with strong CYP3A inducers is contraindicated and dose adjustment is recommended for co-administration with the moderate CYP3A inducer rifabutin.

The pharmacokinetic profile of doravirine supports its use across diverse populations living with HIV-1.

pivotal non-inferiority phase III trials (DRIVE-FORWARD, ClinicalTrials.gov NCT02275780; DRIVE-AHEAD, ClinicalTrials.gov NCT02403674), doravirine, as part of a combination therapy, demonstrated robust antiretroviral efficacy and a favorable safety profile $[4,5]$. Additionally, doravirine had an improved neuropsychiatric profile compared with efavirenz and a favorable lipid profile compared with efavirenz or darunavir [4, 5]. Based on these data, doravirine $100 \mathrm{mg}$ administered orally once daily in combination with other antiretroviral agents, and as part of a three-drug singletablet regimen with lamivudine (3TC) $300 \mathrm{mg}$ and tenofovir disoproxil fumarate (TDF) $300 \mathrm{mg}$, is indicated for use in adults with HIV-1 infection [8, 9]. In the USA, it is indicated for those with no prior antiretroviral treatment history or to replace the current antiretroviral regimen in those who are virologically suppressed on a stable antiretroviral regimen with no history of treatment failure and no known substitutions associated with resistance to doravirine (or to 3TC and TDF for the three-drug single-tablet regimen) $[8,9]$.

This article reviews the pharmacokinetics of doravirine and includes assessments of the potential effects of demographic factors and the DDI profile of doravirine.

\section{Methods of Literature Search}

All sponsor-conducted/funded and published phase I DDI, special population, and pharmacokinetic-profiling trials evaluating doravirine available at the time of writing are included in this review. The phase I trials include those in participants without HIV-1 and a single phase I trial in people living with HIV-1. In addition, this review includes published data from sponsor-conducted phase II and phase III trials, which evaluated safety and efficacy of doravirine in people living with HIV-1. All sponsor data were published in peer-reviewed journals. Details of each trial in this review, including design, sample size, treatments, and trial population, can be found in Table S1. In addition, the bounds of clinical relevance for doravirine based on the totality of the phase I, II, and III data are also discussed, which provide context for the effects on doravirine pharmacokinetics observed in DDI and special population trials.

\section{Doravirine Pharmacokinetics}

Doravirine is a drug with low intrinsic clearance $(3.73 \mathrm{~L} / \mathrm{h}$ following intravenous administration) [10]. Its volume of distribution of $60.5 \mathrm{~L}-$ which is slightly larger than the volume of body water-suggests that doravirine distributes into tissues [10]. Doravirine undergoes oxidative metabolism mediated primarily by cytochrome P450 (CYP) 3A4, and to a lesser extent by CYP3A5 [10]. In an absorption, metabolism, and excretion (AME) study of $\left[{ }^{14} \mathrm{C}\right]$ doravirine, the major circulating component in plasma was unchanged $\left[{ }^{14} \mathrm{C}\right]$ doravirine $(75 \%)$; M9, a metabolite that results from oxidation of the triazolone ring of doravirine, was the most abundant metabolite in plasma, where it accounted for $12.9 \%$ of the drug-related material [10]. M9 was not active against HIV reverse transcriptase in vitro. In addition, M9 was the major metabolite excreted in urine and feces $(\sim 39 \%$ and $\sim 16 \%$ of absorbed dose, respectively). Other measurable metabolites in urine accounted for $<5 \%$ of the absorbed dose. Only a small proportion of doravirine was excreted unchanged in urine $(6.3-13 \%)[10,11]$, and based on the mass balance and excretion of doravirine in the $\left[{ }^{14} \mathrm{C}\right] \mathrm{AME}$ study, biliary excretion is anticipated to be minor. Thus, excretion of unchanged drug is not a major pathway in the elimination of doravirine [10].

Following administration of single oral doses of doravirine (6-1200 mg) to healthy men, doravirine is rapidly absorbed with a median time to maximum plasma concentration $\left(T_{\max }\right)$ of 1-4 h [11]. Plasma concentrations declined in a single exponential phase, with an apparent terminal half-life of 12-19 h (Fig. 1). Plasma area under the concentration-time curve from time zero to infinity $\left(\mathrm{AUC}_{0-\infty}\right)$, maximum plasma concentration $\left(C_{\max }\right)$, and plasma concentration at $24 \mathrm{~h}$ postdose $\left(C_{24}\right)$ increased in a slightly less than dose-proportional manner over the 6-1200 $\mathrm{mg}$ dose range. Median time to steady state was $\sim 2$ days, and mean area under the concentration-time curve from time zero to $24 \mathrm{~h}$ post-dose $\left(\mathrm{AUC}_{0-24}\right)$, $C_{24}$, and $C_{\max }$ accumulation ratios (geometric mean ratio [GMR] Day 10/Day 1) were 1.2-1.4 [11]. These data are consistent with the apparent terminal half-life and indicate time-independent pharmacokinetics. Multiple-dose pharmacokinetics are supportive of once-daily dosing of doravirine [11], and it has been shown that plasma concentrations following 7 days of once-daily dosing with $100 \mathrm{mg}$ of doravirine are maintained above the half maximal effective concentration $\left(\mathrm{IC}_{50}\right)$ for inhibition of wild-type virus for $72 \mathrm{~h}$ after the final dose in adults without HIV infection [12]. 


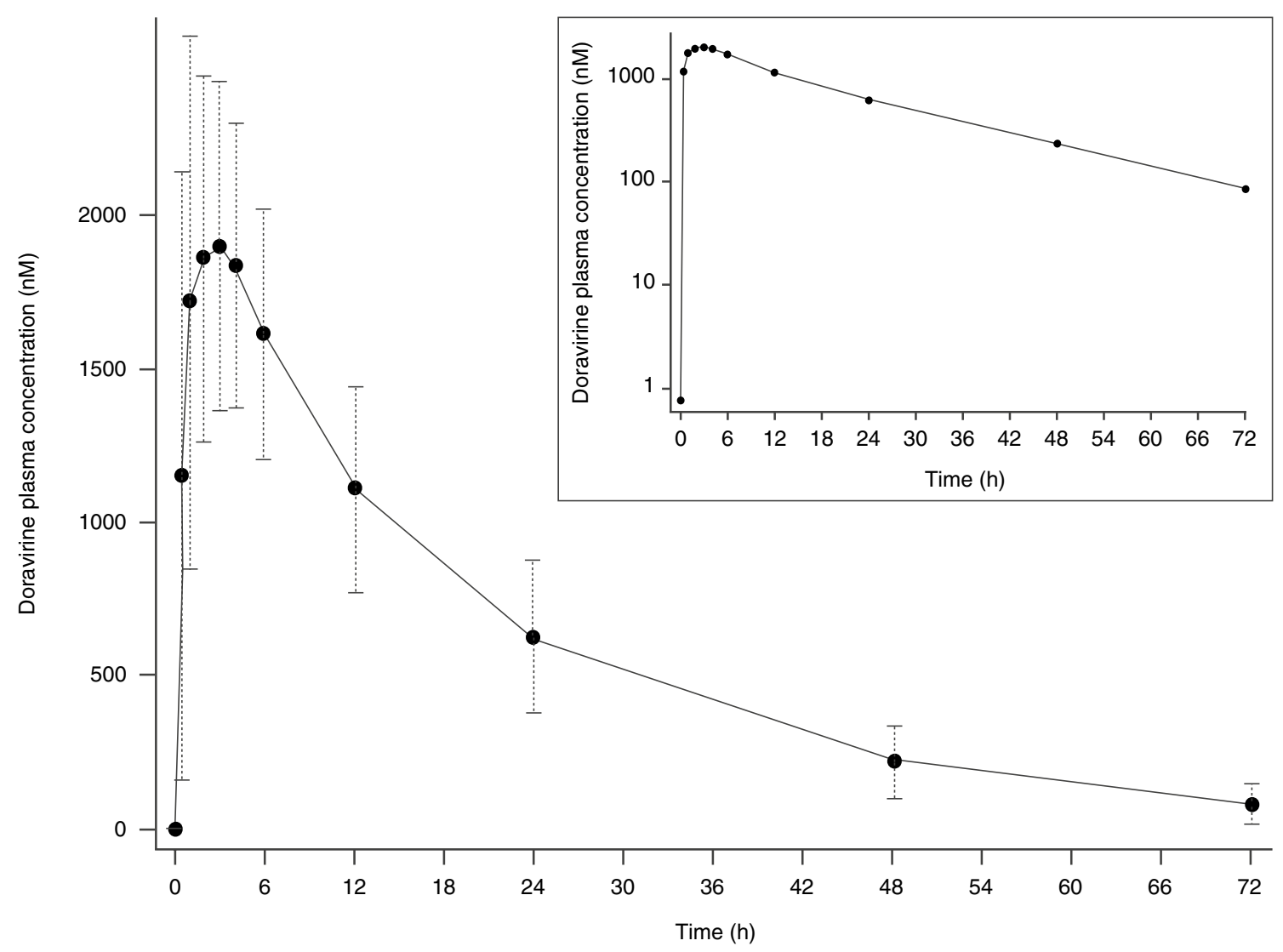

Fig. 1 Mean $( \pm$ SD) doravirine plasma concentration-time profile following single oral dose administration of doravirine 100 mg in healthy individuals $(\mathrm{N}=24)$. The inset shows the same data plotted on a semi-log scale. $S D$ standard deviation

The pharmacokinetics of doravirine in individuals with HIV-1 infection were similar to those in healthy individuals $[13,14]$. Based on a population pharmacokinetic analysis of individuals with $(n=959)$ and without $(n=341)$ HIV-1 infection, individuals with HIV-1 infection receiving doravirine $100 \mathrm{mg}$ once daily have a doravirine geometric mean (\% coefficient of variation) $\mathrm{AUC}_{0-24}$ of $37.8 \mu \mathrm{M} \cdot \mathrm{h}(27.0 \%)$, $C_{24}$ of $930 \mathrm{nM}(41.6 \%)$, and $C_{\max }$ of $2260 \mathrm{nM}(18.4 \%)$ [14]. Corresponding steady-state $\mathrm{AUC}_{0-24}, C_{24}$, and $C_{\max }$ in healthy individuals following administration of $100 \mathrm{mg}$ once daily were $41.1 \mu \mathrm{M} \cdot \mathrm{h}, 902 \mathrm{nM}$, and $2880 \mathrm{nM}$, respectively [15]. Therefore, findings from trials evaluating doravirine pharmacokinetics carried out in participants without HIV-1 infection are expected to be applicable to those with HIV infection.

\section{Definition of the Bounds of Clinical Relevance}

The term "bounds of clinical relevance" refers to the range of doravirine pharmacokinetic values relative to those associated with the recommended dose of $100 \mathrm{mg}$ once daily at steady state where safety and efficacy are expected to be comparable to the clinical dose. When altered pharmacokinetic exposure of doravirine falls within these bounds, safety and efficacy are expected to be comparable to those of $100 \mathrm{mg}$ once-daily doravirine. The definition of clinical relevance bounds for doravirine is based on demonstrated efficacy and safety in the phase I, IIb, and III trials, as described below.

Exposure-response analyses [14] of efficacy endpoints from the two phase III trials $[4,5]$ were used to identify the lower bound of clinical relevance for doravirine, which was defined with respect to steady-state $C_{24}$; maintenance of minimal effective trough levels is typically associated with efficacy for antiretroviral therapies [16]. Based on analyses for the proportion of individuals achieving HIV-1 RNA $<50$ copies $/ \mathrm{mL}$ (virologic response) and occurrence of virologic failure at week 48 , both exposure-response relationships were generally flat over the entire range of doravirine steadystate $C_{24}$ values from the phase III trials, except for a slight decrease in efficacy in individuals with the lowest $10 \%$ of doravirine steady-state $C_{24}$ values [14]. Above the tenth percentile of doravirine steady-state $C_{24}$ values, there were no meaningful changes in the exposure-response relationships 
for virologic response and failure across the entire range of doravirine steady-state $C_{24}$ values [14]. The observed exposure-response trends in the first decile of doravirine steadystate $C_{24}$ values were likely driven by individuals with lower adherence, and therefore lower efficacy rates, rather than reflecting a true decrease in response at lower exposures. In fact, flat exposure- and dose-response relationships were observed over the 25-200 mg once-daily dose range in the phase IIb trial [14]. Nevertheless, the tenth percentile of doravirine steady-state $C_{24}$ values observed in phase III, corresponding to a $40 \%$ decrease in doravirine $C_{24}$, was set as a conservative lower bound for clinical relevance with respect to efficacy. Steady-state $C_{24}$ values above this bound are expected to correspond to efficacy similar to the $100 \mathrm{mg}$ once-daily dose.

A $40 \%$ decrease in doravirine $C_{24}$ also corresponds approximately to the $C_{24}$ values associated with the $50 \mathrm{mg}$ once-daily dose and is nearly twice the $C_{24}$ associated with the $25 \mathrm{mg}$ once-daily dose [14], which were studied in the phase IIb trial and had efficacy similar to $100 \mathrm{mg}$ once daily [17]. Even at this decreased $C_{24}$, doravirine plasma concentrations exceed the pharmacokinetic target of $78 \mathrm{nM}$, which is greater than 6-fold the in vitro $\mathrm{IC}_{50}$ for inhibition of wildtype virus, and exceeds $\mathrm{IC}_{50}$ values for common single resistance mutations (K103N, Y181C, G190A), and of the K103N/Y181C double mutant [16, 18, 19].

Steady-state AUC was selected as the exposure measure from which to judge clinical relevance from a safety perspective, as this parameter is an integration of concentrations over the 24-h dosing interval in which individuals are exposed to doravirine at steady state. In phase I trials, there was no evidence that the incidence of overall AEs or specific AEs was temporally associated with doravirine $T_{\max }[11,15$, 20-31], therefore suggesting that $C_{\max }$ does not play a major role in safety or tolerability. In the phase IIb trial, there was no evidence of exposure- or dose-related toxicities across the range of 25-200 mg doses evaluated, and no meaningful association between doravirine steady-state exposure and the incidence of neuropsychiatric AEs or fasting lipid levels that would further limit the exposure of doravirine from a safety perspective [17].

Concomitant use of moderate and strong CYP3A inhibitors, which are expected to be associated with 2- to 3-fold higher doravirine exposures relative to the $100 \mathrm{mg}$ oncedaily dose, were not prohibited in the pivotal phase III DRIVE-FORWARD trial [5]; however, they were prohibited in the DRIVE-AHEAD trial due to potential interactions with the comparator regimen [4]. In the phase III trials, the $100 \mathrm{mg}$ once-daily dose was generally well tolerated and no treatment-related AEs of concern were identified [4, 5].

For doravirine steady-state exposures at least 3-fold those observed with the $100 \mathrm{mg}$ once-daily dose in the phase III trials, there were no safety signals in short-term clinical pharmacology trials. Specifically, multiple doses of up to $750 \mathrm{mg}$ once daily for 10 days and single doses of up to $1200 \mathrm{mg}$ doravirine [11] were generally well tolerated and provided exposure multiples of $\sim 3.7$ - and $\sim 6.5$-fold, respectively, relative to the steady-state AUC values observed following administration of $100 \mathrm{mg}$ once-daily doravirine. In addition, a single dose of $1200 \mathrm{mg}$ doravirine had no clinically meaningful effect on QTc values [32] at $~ 4.3-$ and 3.3-fold exposure multiples to $C_{\max }$ and $\mathrm{AUC}_{0-24}$, respectively. Thus, based on the totality of clinical experience for doravirine, increases in exposure up to $\sim 3$-fold are not clinically meaningful.

\section{Effect of Demographic Factors}

The effects of demographic factors including age, gender, hepatic impairment, and renal impairment on doravirine pharmacokinetics were evaluated in dedicated phase I trials in participants without HIV-1 infection [22, 24, 25]. In addition, a population pharmacokinetic analysis of individuals with $(n=959)$ and without $(n=341)$ HIV-1 infection was conducted across the phase I, II, and III trials to evaluate the effects of these factors-as well as body weight, body mass index (BMI), race, or ethnicity—on doravirine pharmacokinetics [14].

\subsection{Age}

Physiological changes that occur with aging can result in altered drug pharmacokinetics in older compared with younger people [33]. As the population of people living with HIV-1 is aging [34], evaluation of doravirine in the older population was essential.

The effect of age on doravirine pharmacokinetics was investigated in a phase I trial of healthy elderly men and women (aged 65-80 years) compared with healthy young men and women (18-50 years); results showed that age did not have a clinically meaningful effect on the pharmacokinetics of doravirine among these age groups as the observed changes in $\mathrm{AUC}_{0-\infty}, C_{\max }$, and $C_{24}$ were $<20 \%$ [22] (Table 1, Fig. 2). Similarly, in a population pharmacokinetic analysis [14], although age was identified as a significant covariate for doravirine clearance $\left(\mathrm{AUC}_{0-24}\right.$ was $30 \%$ higher for individuals with HIV-1 infection aged $\geq 65$ years compared with those aged $<65$ years), the effect was consistent with the observations from the phase I trial, and not clinically meaningful as the increase falls within the clinical bounds described above. Similar findings were previously identified for other HIV treatments, where it was reported that age did not have a clinically relevant effect on the pharmacokinetics of boosted darunavir, dolutegravir, and lamivudine in people 
living with HIV, though boosted darunavir exposure was modestly increased in older people [35].

\subsection{Gender}

Differences in drug absorption, distribution, metabolism, and excretion due to physiological differences between genders can result in pharmacokinetic differences [36]. CYP3A4, the enzyme primarily responsible for doravirine metabolism [10], has been shown in a meta-analysis to have significantly greater hepatic activity in women than in men, though no difference in intestinal CYP3A activity was observed [37]. However, the clinical relevance of this difference is unclear [37].

The effect of gender on doravirine pharmacokinetics was investigated in a trial comparing the pharmacokinetics between women and men [22] (Table 1, Fig. 2). Although $C_{\max }$ was shown to be slightly higher $(42 \%)$ in women than in men, any differences in pharmacokinetics due to gender were not considered clinically meaningful [22]. In line with these results, a population pharmacokinetic analysis [14] found no statistically significant effect of gender on doravirine pharmacokinetics. Taken together, the results do not indicate a need for dose adjustment based on gender.

\subsection{Other Characteristics}

A population pharmacokinetic analysis [14] also showed that there were no clinically meaningful effects on doravirine pharmacokinetics due to body weight, BMI, race, or ethnicity (Fig. 2). Race and ethnicity did not have any statistically significant effects on doravirine pharmacokinetics [14]. While weight $(<64.5 \mathrm{~kg}, 64.5<83 \mathrm{~kg}, \geq 83 \mathrm{~kg}$ ) was identified as a significant covariate, the magnitude of its effect was shown to be small (differences in $\mathrm{AUC}_{0-24}, C_{24}$, and $C_{\max }$ were all $<10 \%$, hence exposure was within the clinical bounds), as were differences in $\mathrm{AUC}_{0-24}$ and $C_{\max }$ in individuals with a BMI defined as underweight $\left(<18.5 \mathrm{~kg} / \mathrm{m}^{2}\right)$, pre-obese $\left(25.0-29.99 \mathrm{~kg} / \mathrm{m}^{2}\right)$, or obese $\left(\geq 30.0 \mathrm{~kg} / \mathrm{m}^{2}\right)$ compared with individuals in the normal range $(18.5-24.99 \mathrm{~kg} /$ $\mathrm{m}^{2}$ ) [14]. Therefore, no dose adjustments for doravirine are required for any of these demographic factors.

\section{Pharmacokinetics in Special Populations}

\subsection{Hepatic Impairment}

Liver disease affects $6-11 \%$ of people living with HIV in the USA [38] and can result from a variety of causes, such as chronic hepatitis B or C infection, heavy alcohol

Table 1 Summary of the effect of demographic factors/disease/food on doravirine pharmacokinetics

\begin{tabular}{|c|c|c|c|c|c|c|c|}
\hline \multirow[t]{2}{*}{ Factor } & \multirow[t]{2}{*}{ Dosing } & \multirow[t]{2}{*}{ Comparison } & \multicolumn{4}{|c|}{ Doravirine GMR (90\% CI) } & \multirow[t]{2}{*}{ Reference } \\
\hline & & & $\mathrm{AUC}_{0-\infty}$ & $\mathrm{AUC}_{0-24}$ & $C_{\max }$ & $C_{24}$ & \\
\hline \multirow[t]{2}{*}{ Age } & $\begin{array}{l}\text { Doravirine } \\
100 \mathrm{mg} \mathrm{SD}\end{array}$ & $\begin{array}{r}\text { Elderly men/ } \\
\text { young men }\end{array}$ & $0.85(0.67-1.10)$ & - & $0.92(0.73-1.16)$ & $0.81(0.59-1.11)$ & {$[22]$} \\
\hline & $\begin{array}{l}\text { Doravirine } \\
100 \mathrm{mg} \mathrm{SD}\end{array}$ & $\begin{array}{l}\text { Elderly women/ } \\
\text { young women }\end{array}$ & $0.97(0.79-1.19)$ & - & $1.18(0.98-1.42)$ & $0.94(0.72-1.21)$ & {$[22]$} \\
\hline Gender & $\begin{array}{l}\text { Doravirine } \\
100 \mathrm{mg} \mathrm{SD}\end{array}$ & Women/men & $1.20(1.03-1.40)$ & - & $1.42(1.23-1.64)$ & $1.02(0.84-1.24)$ & {$[22]$} \\
\hline $\begin{array}{l}\text { Hepatic impair- } \\
\text { ment }\end{array}$ & $\begin{array}{l}\text { Doravirine } \\
100 \mathrm{mg} \mathrm{SD}\end{array}$ & $\begin{array}{l}\text { Moderate hepatic } \\
\text { impairment/ } \\
\text { normal hepatic } \\
\text { function }\end{array}$ & $0.99(0.72-1.35)$ & $0.93(0.74-1.18)$ & $0.90(0.66-1.24)$ & $0.99(0.74-1.33)$ & {$[25]$} \\
\hline Renal impairment & $\begin{array}{l}\text { Doravirine } \\
100 \mathrm{mg} \mathrm{SD}\end{array}$ & $\begin{array}{l}\text { Severe renal } \\
\text { impairment/ } \\
\text { normal renal } \\
\text { function }\end{array}$ & $1.43(1.00-2.04)$ & - & $0.83(0.61-1.15)$ & $1.38(0.99-1.92)$ & {$[24]$} \\
\hline \multirow[t]{2}{*}{ Food } & $\begin{array}{l}\text { Doravirine } \\
100 \mathrm{mg} \mathrm{SD}\end{array}$ & Fed/fasted & $1.16(1.06-1.26)$ & - & $1.03(0.89-1.19)$ & $1.36(1.19-1.55)$ & {$[23]$} \\
\hline & $\begin{array}{l}\text { Doravirine } \\
100 \mathrm{mg} / \\
\text { lamivudine } \\
300 \mathrm{mg} / \mathrm{TDF} \\
300 \mathrm{mg} \mathrm{SD}\end{array}$ & Fed/fasted & $1.10(1.01-1.20)$ & - & $0.95(0.80-1.12)$ & $1.26(1.13-1.41)$ & {$[23]$} \\
\hline
\end{tabular}

$A U C_{0-24}$ area under the concentration-time curve from time zero to $24 \mathrm{~h}, A U C_{0-\infty}$ area under the concentration-time curve from time zero to infinity, $C_{24}$ plasma concentration $24 \mathrm{~h}$ post-dose, $C I$ confidence interval, $C_{\max }$ maximum plasma concentration, GMR geometric mean ratio, $S D$ single dose, $T D F$ tenofovir disoproxil fumarate 


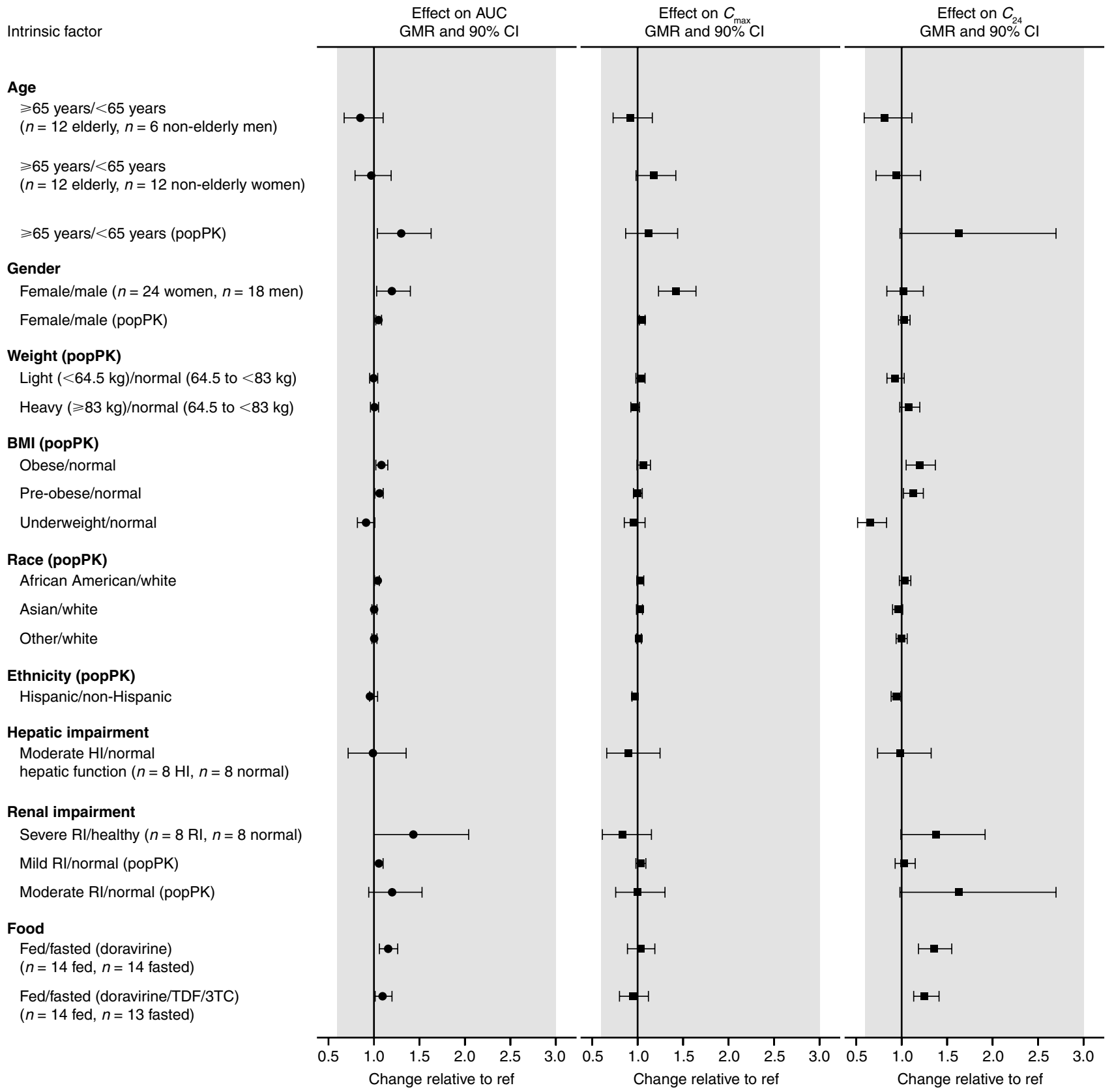

Fig. 2 Visual summary of the effect of demographic factors/disease/ food on doravirine exposure. Modified from Yee et al. [14]. Copyright (C) American Society for Microbiology, Antimicrob Agents Chemother, vol 63, 2019, e02502-18, DOI 10.1128/AAC.0250218. 3TC lamivudine, $A U C$ area under the concentration-time curve, $B M I$ body mass index, $C_{24}$ plasma concentration $24 \mathrm{~h}$ post-dose,

consumption, and medication-induced toxicity [39]. Therefore, hepatic impairment can reasonably be expected to affect a sizeable proportion of people living with HIV; for those receiving antiretroviral therapy, this impairment may alter the pharmacokinetics of CYP3A-metabolized antiretroviral drugs [40]. A trial of doravirine in participants without
$C_{\max }$ maximum plasma concentration, $C I$ confidence interval, $G M R$ geometric mean ratio, $H I$ hepatic impairment, popPK population pharmacokinetics, ref reference value, $R I$ renal impairment, $T D F$ tenofovir disoproxil fumarate. Shaded region represents the clinical bounds

HIV infection showed similar doravirine pharmacokinetics in the presence or absence of moderate hepatic impairment, and indicated that moderate hepatic impairment had no clinically meaningful effect on doravirine pharmacokinetics (Table 1, Fig. 2) and that dose adjustment is not required for individuals with moderate or mild hepatic impairment 
[25]. Doravirine was not studied in individuals with severe hepatic impairment $[8,9]$.

\subsection{Renal Impairment}

Chronic kidney disease affects 5-23\% of people living with HIV in the USA [38], and may result from a number of causes, including HIV infection itself, co-morbidities such as diabetes, and toxicity associated with certain antiretroviral drugs [38, 41]. Given that doravirine has minimal renal excretion $(<10 \%)[10,11]$, renal impairment was not expected to have a clinically meaningful effect on doravirine pharmacokinetics. In a clinical trial [24], severe renal impairment was shown to have an effect on doravirine pharmacokinetics, moderately increasing exposure by $43 \%$ (Table 1, Fig. 2). Increased oral bioavailability, decreased clearance via decreased expression of gut/liver metabolic enzymes in rats, or enzyme inhibition by uremic toxins in individuals with severe renal impairment have been suggested to result in increased AUC, $C_{\max }$, and apparent terminal half-life of drugs eliminated via CYP3A-mediated metabolism [42]. However, the observed changes in doravirine pharmacokinetics were not anticipated to be clinically meaningful, as they fall within the clinical bounds of $(0.6,3.0)$ [24]. It was therefore concluded that doravirine may be administered to individuals with HIV-1 infection and mild, moderate, or severe renal impairment without dose adjustment [24]. This finding was supported by a population pharmacokinetic analysis that assessed the impact of renal function, as determined by the Modification of Diet in Renal Disease study estimated glomerular filtration rate, on doravirine pharmacokinetics across the phase I, II, and III population, and found no statistically significant effect of renal function on doravirine pharmacokinetics [14].

\section{Food Effects}

The NNRTIs etravirine and rilpivirine are recommended to be taken following and with a meal, respectively; exposure to each of these drugs is substantially decreased in a fasted versus a fed state $[43,44]$. To investigate the effect of food on doravirine pharmacokinetics, doravirine was administered following a fast and following a high-fat, high-calorie meal, both alone and as part of a single-tablet regimen combined with 3TC and TDF [23]. Although doravirine AUC ${ }_{0-\infty}$ and $C_{24}$ were slightly increased in the fed state compared with fasted state, by $10-36 \%$, these changes were not considered clinically meaningful (Table 1, Fig. 2), suggesting doravirine may be administered with or without food [23]. In both phase III trials, doravirine was administered without regard to meals $[4,5]$.

\section{In Vitro Drug-Drug Interaction (DDI) Assessment}

In vitro assessment confirmed that oxidative metabolism of doravirine is mediated mainly by CYP3A4, with some minor contribution by CYP3A5 [10]. As a result, doravirine pharmacokinetics may be altered in the presence of CYP3A modulators. Doravirine did not inhibit the activity of CYP1A2, 2B6, 2C8, 2C9, 2C19, 2D6, or 3A4, or uridinediphosphate glucuronosyltransferase (UGT)1A1 ( $\mathrm{IC}_{50}>100 \mu \mathrm{M}$ for all enzymes) [45], at concentrations well above the doravirine mean peak plasma concentration of $2.26 \mu \mathrm{M}$, which corresponds to a maximal unbound concentration of $0.54 \mu \mathrm{M}$. Additionally, doravirine does not induce CYP1A2 or CYP2B6 mRNA or enzyme activity in vitro [45], and although a low level of CYP3A4 mRNA induction was observed with $10 \mu \mathrm{M}$ doravirine, no effect on CYP3A4 enzyme activity was observed and it was projected to have no clinically meaningful impact [45]. Doravirine is a substrate of $\mathrm{P}$-gp in vitro; however, $\mathrm{P}$-gp does not appear to have a significant role in the disposition of doravirine [10]. Doravirine is not a substrate of the breast cancer receptor protein (BCRP), organic anion-transporting polypeptide (OATP)1B1, or OATP1B3 [45], and, since renal excretion is not a major route of elimination of doravirine, it is therefore not likely to be affected by modulation of major hepatic or renal drug transporters [10]. In addition, doravirine is unlikely to cause DDIs via inhibition of major drug transporters, including P-gp, OATP1B1, OATP1B3, organic anion transporter (OAT)1, OAT3, organic cation transporter (OCT)2, multidrug and toxin extrusion protein (MATE)1, MATE2K, and bile salt extrusion pump (BSEP) [45]. Systemic exposure to doravirine is not likely to cause DDIs via inhibition of BRCP; however, with an $\mathrm{IC}_{50}$ value of $51 \mu \mathrm{M}$, inhibition of intestinal BCRP by doravirine is possible [45].

\section{In Vivo DDI Assessment}

Polypharmacy in individuals with HIV infection is common, and co-administration of antiretroviral drugs with drugs for treating co-morbidities of HIV-1 infection is often required, leading to the potential for DDIs [46]. One study estimated that potential DDIs occurred in approximately two-thirds of people receiving antiretroviral therapy for HIV infection; around one-quarter of these potential interactions were between antiretroviral medications themselves [46]. Common co-morbidities in individuals with HIV infection that require treatment include hepatitis $\mathrm{C}$ virus $(\mathrm{HCV})$ infection, tuberculosis, diabetes, and hyperlipidemia [1, 38, 47].

The following sections discuss the clinical investigations of potential DDIs between doravirine and a range of drug 
classes likely to be co-administered, including concomitant antiretroviral drugs and medications for treating common co-morbidities. These findings are also extrapolated to other medications on the basis of known pharmacokinetic characteristics.

\subsection{Doravirine and Antiretroviral Drugs for the Treatment of HIV Infection}

\subsubsection{Doravirine and Nucleoside Reverse Transcriptase Inhibitors (NRTIs)}

To support the development of a single-tablet regimen with doravirine, two DDI trials were conducted with doravirine and two commonly used NRTIs, 3TC and TDF [31]. 3TC and tenofovir are primarily eliminated via organic cationic secretion, glomerular filtration, and active tubular secretion, pathways that are not affected by doravirine $[48,49]$. Neither NRTI is expected to affect CYP metabolism [48, 49]. Consistent with the disposition of all three agents, the DDI trials demonstrated no clinically meaningful effect on doravirine, tenofovir, or 3TC pharmacokinetics (Tables 2 and 3, Figs. 3 and 4), supporting co-administration without the need for dose adjustment [31] and the co-formulation of these agents into a single-tablet regimen.

Abacavir and emtricitabine have no known interactions with CYP3A [3]. Abacavir is known to be a substrate of UGT1A1 and alcohol dehydrogenase, neither of which are likely to be impacted by doravirine [45]. Hence, interactions of abacavir or emtricitabine with doravirine are unlikely. Doravirine is not expected to cause any significant interactions with P-gp, BCRP, OATP1B1, and OATP1B3 [45], for which tenofovir alafenamide (TAF) is a substrate [50]. As the prescribing information for TAF does not suggest that it inhibits or induces CYP3A (TAF did not affect the pharmacokinetics of the sensitive CYP3A substrate midazolam) [50], a DDI with doravirine is not expected, and therefore doravirine and TAF may be co-administered. Furthermore, phase III trials have demonstrated the safety and efficacy of doravirine when co-administered with TDF and 3TC, or with other NRTIs such as emtricitabine, TAF, or abacavir $[4,5]$.

\subsubsection{Doravirine and Non-Nucleoside Reverse Transcriptase Inhibitors (NNRTIs)}

Due to associated psychiatric and central nervous system effects of the NNRTI efavirenz [51], doravirine may be a suitable alternative for individuals who have difficulties tolerating efavirenz. Efavirenz is a known CYP3A inducer, and in order to maintain viral suppression during regimen switch, the interaction of doravirine with residual efavirenz concentrations and the persistent CYP3A4 induction effects following cessation of efavirenz [52] should be considered.
Doravirine exposure was transiently decreased in the days following a switch from efavirenz to doravirine in healthy adults (Table 2, Fig. 3) [15]. Following discontinuation of efavirenz, efavirenz concentrations exceeded the therapeutic threshold (1000 ng/mL [53]) until Day 3, and at this time doravirine concentrations exceeded the pharmacokinetic target for efficacy (six times the $\mathrm{IC}_{50}$ ) [15]; however, doravirine concentrations remained below the bounds for clinical efficacy through Day 14. Nevertheless, during this transient decrease in doravirine concentrations, dose adjustment is not considered necessary as individuals with HIV-1 infection are expected to be virologically suppressed prior to switch and will continue to receive other antiretroviral agents during switch, which supports the low likelihood of viral rebound or development of viral resistance [15]. Switching to a doravirine-based regimen was assessed in a phase III trial (DRIVE-SHIFT; ClinicalTrials.gov NCT02397096) that evaluated switching from a stable antiretroviral regimen to a single-tablet regimen of doravirine $100 \mathrm{mg}$ with 3TC $300 \mathrm{mg}$ and TDF $300 \mathrm{mg}$ (DOR/TDF/3TC) [54]. In this trial, a similar high level of antiretroviral efficacy of DOR/3TC/TDF was observed in participants who switched from an efavirenz-based regimen and those who switched from another baseline regimen, showing that the transient decrease in doravirine concentration is not clinically meaningful [55].

As doravirine was shown not to be a significant inducer or inhibitor of a number of CYP enzymes in vitro [45], and in vivo doravirine did not significantly impact the pharmacokinetics of midazolam (Table 3) [11], doravirine is not expected to cause clinically meaningful DDIs with etravirine, which is a substrate for CYP3A, CYP2C9, and CYP2C19 enzymes [43], or with nevirapine, which is a substrate for CYP3A and CYP2B6 enzymes [56]. Etravirine and nevirapine are also inducers of CYP3A4 [3]. Based on the transient reduced exposure of doravirine following switch from efavirenz (a CYP3A inducer) [15], there is potential that switch from etravirine or nevirapine would result in a minor inductive effect on doravirine pharmacokinetics. However, based on the shorter half-lives of these agents [43, $51,56]$, it is unlikely that the duration of effect would exceed that of efavirenz, and therefore switch from etravirine or nevirapine to doravirine is also supported. Rilpivirine does not induce or inhibit CYP3A4, and although it is a substrate for CYP3A4 [3], it is unlikely to result in DDIs with doravirine, similar to other CYP3A substrates [26].

\subsubsection{Doravirine and HIV-1 Boosted and Unboosted Protease Inhibitors (PIs)}

Ritonavir is an HIV-1 PI commonly used as a pharmacokinetic-enhancing agent for other HIV-1 drugs metabolized by CYP3A4, including other PIs [3, 57]. Because it is a 
Table 2 Summary of doravirine drug-drug interactions: the effect of concomitant drugs on doravirine pharmacokinetics

\begin{tabular}{|c|c|c|c|c|c|c|}
\hline \multirow[t]{2}{*}{$\begin{array}{l}\text { Concomitant medication } \\
\text { dosing }\end{array}$} & \multirow[t]{2}{*}{ Doravirine dosing } & \multicolumn{4}{|c|}{$\begin{array}{l}\text { Doravirine GMR }(90 \% \mathrm{CI}) \text { [(doravirine + concomitant medication }) / \\
\text { doravirine alone] }\end{array}$} & \multirow[t]{2}{*}{ Reference } \\
\hline & & $\mathrm{AUC}_{0-\infty}$ & $\mathrm{AUC}_{0-24}$ & $C_{\max }$ & $C_{24}$ & \\
\hline TDF $300 \mathrm{mg}$ once daily & Doravirine $100 \mathrm{mg} \mathrm{SD}$ & $0.95(0.80-1.12)$ & - & $0.80(0.64-1.01)$ & $0.94(0.78-1.12)$ & {$[31]$} \\
\hline $\begin{array}{l}\text { TDF } 300 \mathrm{mg}+\text { lamivudine } \\
300 \mathrm{mg}\end{array}$ & Doravirine $100 \mathrm{mg} \mathrm{SD}$ & $0.96(0.87-1.06)$ & - & $0.97(0.88-1.07)$ & $0.94(0.83-1.06)$ & {$[31]$} \\
\hline $\begin{array}{l}\text { Efavirenz prior dosing } \\
600 \mathrm{mg} \text { once daily }\end{array}$ & $\begin{array}{l}\text { Doravirine } 100 \mathrm{mg} \mathrm{SD} \\
\text { (Day } 1 \text { following } \\
\text { efavirenz cessation) }\end{array}$ & - & $0.38(0.33-0.45)$ & $0.65(0.58-0.73)$ & $0.15(0.10-0.23)$ & [15] \\
\hline $\begin{array}{l}\text { Efavirenz prior dosing } \\
600 \mathrm{mg} \text { once daily }\end{array}$ & $\begin{array}{l}\text { Doravirine } 100 \mathrm{mg} \text { once } \\
\text { daily (Day } 14 \text { following } \\
\text { efavirenz cessation) }\end{array}$ & - & $0.68(0.58-0.80)$ & $0.86(0.77-0.97)$ & $0.50(0.39-0.64)$ & [15] \\
\hline $\begin{array}{l}\text { Ritonavir } 100 \mathrm{mg} \text { once } \\
\text { daily }\end{array}$ & Doravirine $50 \mathrm{mg} \mathrm{SD}$ & $3.54(3.04-4.11)$ & - & $1.31(1.17-1.46)$ & $2.91(2.33-3.62)$ & {$[26]$} \\
\hline $\begin{array}{l}\text { Dolutegravir } 50 \mathrm{mg} \text { once } \\
\text { daily }\end{array}$ & $\begin{array}{l}\text { Doravirine } 200 \mathrm{mg} \\
\text { once daily }\end{array}$ & - & $1.00(0.89-1.12)$ & $1.06(0.88-1.28)$ & $0.98(0.88-1.09)$ & {$[20]$} \\
\hline $\begin{array}{l}\text { Elbasvir } 50 \mathrm{mg}+ \\
\text { grazoprevir } 200 \mathrm{mg} \text { once } \\
\text { daily }\end{array}$ & $\begin{array}{l}\text { Doravirine } 100 \mathrm{mg} \\
\text { once daily }\end{array}$ & - & $1.56(1.45-1.68)$ & $1.41(1.25-1.58)$ & $1.61(1.45-1.79)$ & {$[27]$} \\
\hline $\begin{array}{l}\text { Ledipasvir } 90 \mathrm{mg} / \\
\text { sofosbuvir } 400 \mathrm{mg} \mathrm{SD}\end{array}$ & Doravirine $100 \mathrm{mg} \mathrm{SD}$ & $1.15(1.07-1.24)$ & - & $1.11(0.97-1.27)$ & $1.24(1.13-1.36)$ & {$[27]$} \\
\hline $\begin{array}{l}\text { Ketoconazole } 400 \mathrm{mg} \\
\text { once daily }\end{array}$ & Doravirine $100 \mathrm{mg} \mathrm{SD}$ & $3.06(2.85-3.29)$ & - & $1.25(1.05-1.49)$ & $2.75(2.54-2.98)$ & [26] \\
\hline $\begin{array}{l}\text { Rifampin } 600 \mathrm{mg} \\
\text { once daily }\end{array}$ & Doravirine $100 \mathrm{mg} \mathrm{SD}$ & $0.12(0.10-0.15)$ & - & $0.43(0.35-0.52)$ & $0.03(0.02-0.04)$ & [74] \\
\hline $\begin{array}{l}\text { Rifabutin } 300 \mathrm{mg} \\
\text { once daily }\end{array}$ & Doravirine $100 \mathrm{mg} \mathrm{SD}$ & $0.50(0.45-0.55)$ & - & $0.99(0.85-1.15)$ & $0.32(0.28-0.35)$ & {$[75]$} \\
\hline $\begin{array}{l}\text { Maintenance methadone } \\
20-200 \mathrm{mg} \text { once daily }\end{array}$ & $\begin{array}{l}\text { Doravirine } 100 \mathrm{mg} \\
\text { once daily }\end{array}$ & - & $0.74(0.61-0.90)$ & $0.76(0.63-0.91)$ & $0.80(0.63-1.03)$ & {$[30]$} \\
\hline $\begin{array}{l}\text { Antacid oral suspension } \\
\text { (1600 mg aluminum } \\
\text { hydroxide/1600 mg } \\
\text { magnesium hydrox- } \\
\text { ide/160 mg simethicone) SD }\end{array}$ & Doravirine $100 \mathrm{mg} \mathrm{SD}$ & $1.01(0.92-1.11)$ & - & $0.86(0.74-1.01)$ & $1.03(0.94-1.12)$ & {$[28]$} \\
\hline $\begin{array}{l}\text { Pantoprazole } 40 \mathrm{mg} \\
\text { once daily }\end{array}$ & Doravirine $100 \mathrm{mg} \mathrm{SD}$ & $0.83(0.76-0.91)$ & - & $0.88(0.76-1.01)$ & $0.84(0.77-0.92)$ & [28] \\
\hline
\end{tabular}

strong CYP3A4 inhibitor, ritonavir increases the exposure of drugs_-and "boosts" activity—via inhibition of CYP3A4mediated drug metabolism [57]. Although ritonavir is not anticipated to be used as a pharmacokinetic enhancer for doravirine, the interaction between ritonavir and doravirine was evaluated in the event that doravirine is administered as part of a boosted-PI regimen or used concomitantly with other strong CYP3A inhibitors. Co-administration of doravirine and ritonavir increased doravirine exposure $\sim 3$-fold compared with doravirine alone (Table 2, Fig. 3), consistent with the inhibition of CYP3A4 metabolism, the primary clearance pathway of doravirine [10, 26]. However, $C_{\text {max }}$ increased only by $\sim 30 \%$. In accordance with the clinical bounds described above, these changes in doravirine pharmacokinetics were not considered clinically meaningful, and no dose adjustment is required for co-administration of doravirine and ritonavir [26].

Cobicistat is a strong CYP3A inhibitor used as a pharmacokinetic enhancer for the PIs atazanavir and darunavir [58]. As the CYP3A inhibitor effect is expected to be similar to ritonavir [59], a 3 fold increase in doravirine exposure is expected when the two agents are co-administered.

Several other HIV-1 boosted or unboosted PIs have potential for perpetrating DDIs through modulation of various enzymes and/or transporters, including CYP3A, OATP, UGT1A1, and P-gp [3]. However, the magnitude of CYP3A inhibition for atazanavir, darunavir, indinavir, and saquinavir is not likely to be greater than that observed for ritonavir, 
Table 3 Summary of doravirine drug-drug interactions: the effect of doravirine on the pharmacokinetics of concomitant drugs

\begin{tabular}{|c|c|c|c|c|c|c|}
\hline \multirow[t]{2}{*}{$\begin{array}{l}\text { Concomitant medication } \\
\text { dosing }\end{array}$} & \multirow[t]{2}{*}{ Doravirine dosing } & \multicolumn{4}{|c|}{$\begin{array}{l}\text { Concomitant medication GMR }(90 \% \mathrm{CI})[(\text { doravirine }+ \text { concomitant } \\
\text { medication }) / \text { concomitant medication alone }]\end{array}$} & \multirow[t]{2}{*}{ Reference } \\
\hline & & $\mathrm{AUC}_{0-\infty}$ & $\mathrm{AUC}_{0-24}$ & $C_{\max }$ & $C_{24}$ & \\
\hline \multirow{4}{*}{$\begin{array}{l}\text { TDF } 300 \mathrm{mg} \text { SD + } \\
\text { lamivudine } 300 \mathrm{mg} \text { SD }\end{array}$} & \multirow[t]{4}{*}{ Doravirine $100 \mathrm{mg}$ SD } & Tenofovir: & & & & \\
\hline & & $1.11(0.97-1.28)$ & - & $1.17(0.96-1.42)$ & - & {$[31]$} \\
\hline & & Lamivudine: & & & & \\
\hline & & $0.94(0.88-1.00)$ & - & $0.92(0.81-1.05)$ & - & {$[31]$} \\
\hline Midazolam 2 mg SD & $\begin{array}{l}\text { Doravirine } 120 \mathrm{mg} \\
\text { once daily }\end{array}$ & $0.82(0.70-0.97)$ & - & $1.02(0.81-1.28)$ & - & {$[11]$} \\
\hline $\begin{array}{l}\text { Dolutegravir } 50 \mathrm{mg} \\
\text { once daily }\end{array}$ & $\begin{array}{l}\text { Doravirine } 200 \mathrm{mg} \\
\text { once daily }\end{array}$ & - & $1.36(1.15-1.62)$ & $1.43(1.20-1.71)$ & $1.27(1.06-1.53)$ & {$[20]$} \\
\hline \multirow{4}{*}{$\begin{array}{l}\text { Elbasvir } 50 \mathrm{mg} \\
\text { once daily }+ \\
\text { grazoprevir } 200 \mathrm{mg} \\
\text { once daily }\end{array}$} & \multirow{4}{*}{$\begin{array}{l}\text { Doravirine } 100 \mathrm{mg} \\
\text { once daily }\end{array}$} & Elbasvir: & & & & \\
\hline & & - & $0.96(0.90-1.02)$ & $0.96(0.91-1.01)$ & $0.96(0.89-1.04)$ & {$[27]$} \\
\hline & & Grazoprevir: & & & & \\
\hline & & - & $1.07(0.94-1.23)$ & $1.22(1.01-1.47)$ & $0.90(0.83-0.96)$ & {$[27]$} \\
\hline \multirow{6}{*}{$\begin{array}{l}\text { Ledipasvir } 90 \mathrm{mg} / \\
\text { sofosbuvir } 400 \mathrm{mg} \mathrm{SD}\end{array}$} & \multirow[t]{6}{*}{ Doravirine $100 \mathrm{mg} \mathrm{SD}$} & Ledipasvir: & & & & \\
\hline & & $0.92(0.80-1.06)$ & - & $0.91(0.80-1.02)$ & - & {$[27]$} \\
\hline & & Sofosbuvir: & & & & \\
\hline & & $1.04(0.91-1.18)$ & - & $0.89(0.79-1.00)$ & - & {$[27]$} \\
\hline & & $G S-331007:$ & & & & \\
\hline & & $1.03(0.98-1.09)$ & - & $1.03(0.97-1.09)$ & - & {$[27]$} \\
\hline Metformin $1000 \mathrm{mg}$ SD & $\begin{array}{l}\text { Doravirine } 100 \mathrm{mg} \\
\text { once daily }\end{array}$ & $0.94(0.88-1.00)$ & - & $0.94(0.86-1.03)$ & - & [29] \\
\hline Atorvastatin $20 \mathrm{mg} \mathrm{SD}$ & $\begin{array}{l}\text { Doravirine } 100 \mathrm{mg} \\
\text { once daily }\end{array}$ & $0.98(0.90-1.06)$ & - & $0.67(0.52-0.85)$ & - & {$[21]$} \\
\hline \multirow{6}{*}{$\begin{array}{l}\text { Maintenance methadone } \\
20-200 \mathrm{mg} \text { once daily }\end{array}$} & \multirow{6}{*}{$\begin{array}{l}\text { Doravirine } 100 \mathrm{mg} \\
\text { once daily }\end{array}$} & (R)-methadone: & & & & \\
\hline & & - & $0.95(0.90-1.01)$ & $0.98(0.93-1.03)$ & $0.95(0.88-1.03)$ & {$[30]$} \\
\hline & & (S)-methadone: & & & & \\
\hline & & - & $0.98(0.90-1.06)$ & $0.97(0.91-1.04)$ & $0.97(0.86-1.10)$ & {$[30]$} \\
\hline & & Total methadone: & & & & \\
\hline & & - & $0.96(0.90-1.03)$ & $0.98(0.92-1.03)$ & $0.96(0.87-1.05)$ & {$[30]$} \\
\hline \multirow{4}{*}{$\begin{array}{l}\text { Ethinyl estradiol } 0.03 \mathrm{mg} / \\
\text { levonorgestrel } 0.15 \mathrm{mg} \\
\mathrm{SD}\end{array}$} & \multirow{4}{*}{$\begin{array}{l}\text { Doravirine } 100 \mathrm{mg} \\
\text { once daily }\end{array}$} & Ethinyl estradiol: & & & & \\
\hline & & $0.98(0.94-1.03)$ & - & $0.83(0.80-0.87)$ & - & {$[26]$} \\
\hline & & Levonorgestrel: & & & & \\
\hline & & $1.21(1.14-1.28)$ & - & $0.96(0.88-1.05)$ & - & {$[26]$} \\
\hline
\end{tabular}

$A U C_{0-24}$ area under the concentration-time curve from time zero to $24 \mathrm{~h}, A U C_{0-\infty}$ area under the concentration-time curve from time zero to infinity, $C_{24}$ plasma concentration 24 h post-dose, $C I$ confidence interval, $C_{\max }$ maximum plasma concentration, $G M R$ geometric mean ratio, $S D$ single dose, $T D F$ tenofovir disoproxil fumarate

and lopinavir is not a CYP3A inhibitor [59]. Therefore, these agents are unlikely to have a clinically meaningful effect on doravirine pharmacokinetics, despite being CYP3A4 substrates and/or inhibitors [3]. While lopinavir is considered a moderate inducer when given alone, it is only available for use in combination with ritonavir, and in this setting boosted lopinavir behaves as a CYP3A4 inhibitor, in addition to being a CYP3A4 substrate [3]. Similarly, while tipranavir is considered a CYP3A4 inducer, it is only recommended for use with ritonavir, and the net effect of these two agents is
CYP3A4 inhibition [3]. As doravirine may be concomitantly administered with strong CYP3A inhibitors without dose adjustment [26], a dose adjustment would not be required for boosted tipranavir. Fosamprenavir, the prodrug of amprenavir, is considered a moderate CYP3A inhibitor and weak inducer [3], and therefore the net effect on doravirine exposure following co-administration is unknown. However, if this agent is used in combination with a pharmacokinetic enhancer, it is likely that there would be a net increase in doravirine exposure. 


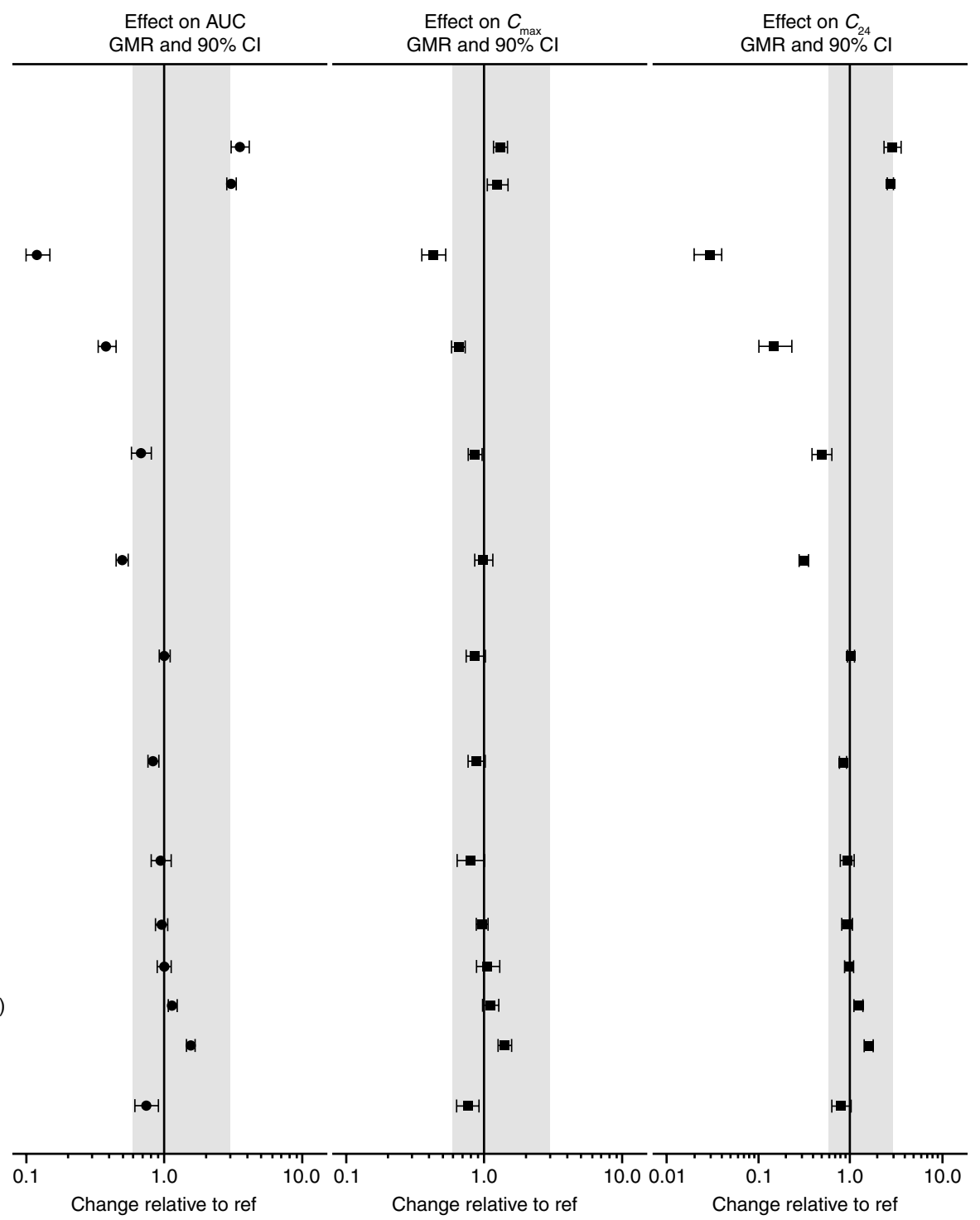

Strong CYP3A inhibitors

Ritonavir $100 \mathrm{mg}$ once daily $(n=8)$

Ketoconazole $400 \mathrm{mg}$ once daily $(n=10)$

Strong CYP3A inducer

Rifampin $600 \mathrm{mg}$ once daily (doravirine + rifampin, $n=10$; doravirine, $n=11$ )

\section{Moderate CYP3A inducers}

Efavirenz prior dosing $600 \mathrm{mg}$ once daily (Day 1 following efavirenz cessation) (with prior efavirenz, $n=17$; without prior efavirenz, $n=20$ )

Efavirenz prior dosing $600 \mathrm{mg}$ once daily (Day 14 following efavirenz cessation) (with prior efavirenz, $n=17$; without prior efavirenz, $n=19$ )

Rifabutin 300 mg once daily (doravirine + rifabutin, $n=12$; doravirine, $n=18$ )

\section{Gastric acid modifiers}

Antacid oral suspension (1600 mg aluminum hydroxide/ $1600 \mathrm{mg}$ magnesium hydroxide/160 mg simethicone) SD $(n=14)$

Pantoprazole $40 \mathrm{mg}$ once daily (doravirine + pantoprazole, $n=13$; doravirine, $n=14$ )

\section{Other interactions}

TDF $300 \mathrm{mg}$ once daily (doravirine + TDF, $n=7$; doravirine, $n=8$ )

TDF 300 mg + lamivudine 300 mg SD $(n=15)$

Dolutegravir $50 \mathrm{mg}$ once daily $(n=11)$

Ledipasvir 90 mg/sofosbuvir 400 mg SD ( $n=14)$

Elbasvir $50 \mathrm{mg}+$ grazoprevir $200 \mathrm{mg}$ once daily ( $n=12)$

Methadone 20-200 mg once daily (methadone + doravirine, $n=14$; doravirine, $n=19$ )

Fig. 3 Visual summary of doravirine DDIs: the effect of concomitant drugs on doravirine exposure. AUC area under the concentrationtime curve, $C_{24}$ plasma concentration $24 \mathrm{~h}$ post-dose, $C_{\max }$ maximum plasma concentration, $C I$ confidence interval, $D D I$ drug-drug interac-

\subsubsection{Doravirine and Integrase Strand Transfer Inhibitors (InSTIs)}

In some instances, an NNRTI may be co-administered with an InSTI [3], and the combination of NNRTIs and InSTIs may offer an alternative to NRTI-based therapies [60]. Dolutegravir has shown good efficacy and tolerability along with a high barrier to resistance [20]; in vitro, low potential for DDIs was reported [61]. It is metabolized by UGT1A1/1A3/1A9 and CYP3A4, and is a substrate for P-gp and BCRP [61]. Although a weak inhibitor of CYP3A in vitro, dolutegravir does not inhibit or induce CYP3A in vivo [62]. In line with this finding, the pharmacokinetics tion, GMR geometric mean ratio, ref reference value, $S D$ single dose, $T D F$ tenofovir disoproxil fumarate. Shaded region represents the clinical bounds

of doravirine ( $200 \mathrm{mg}$ once daily) in healthy subjects were shown to be similar in the presence or absence of dolutegravir (50 mg once daily) (Table 2, Fig. 4) [20]. The modest increases in dolutegravir $\mathrm{AUC}_{0-24}, C_{\max }$, and $C_{24}$ observed at a supratherapeutic doravirine dose of $200 \mathrm{mg}$ once daily, thought to result from inhibition of BCRP in the gut by doravirine, were considered not clinically meaningful (Table 3 , Fig. 4) [20].

Other InSTIs are unlikely to interact with doravirine based on their known metabolism or elimination pathways and their propensity to modulate major CYPs and transporters. For example, elvitegravir is a UGT1A1 and CYP3A4 substrate and CYP2C9 inhibitor, while raltegravir is a 


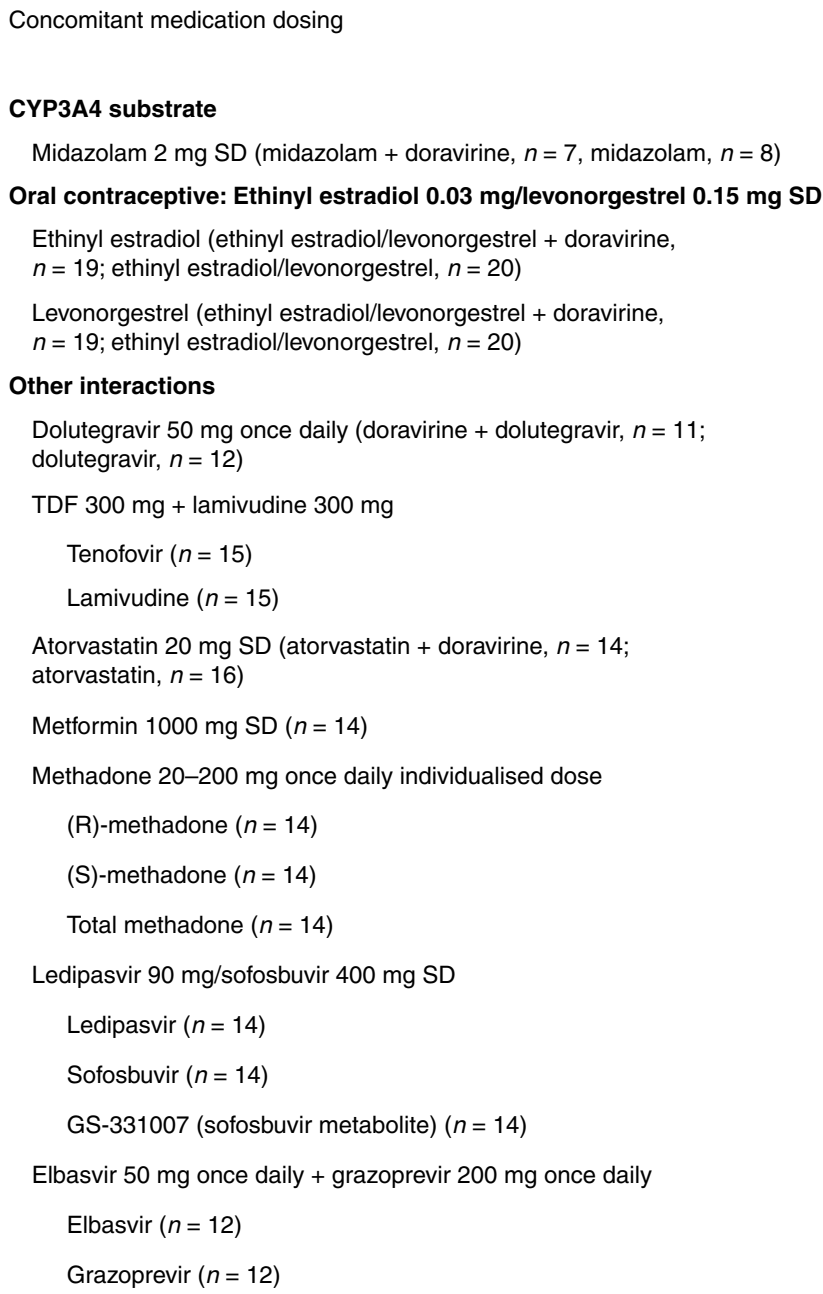

Fig. 4 Visual summary of doravirine DDIs: the effect of doravirine on the exposure of concomitant drugs. $A U C$, area under the concentration-time curve, $C_{\max }$ maximum plasma concentration, $C I$ con-

UGT1A1 substrate [3]; therefore, neither drug is likely to affect CYP3A-mediated metabolism of doravirine via induction or inhibition of CYP3A4. Elvitegravir may be boosted with either cobicistat or ritonavir [3] and, as discussed above, the increases in doravirine expected with these agents are not considered clinically meaningful.

\subsection{Doravirine and Anti-Hepatitis C Virus (HCV) Drugs}

People living with HIV infection are almost six times more likely to be infected with HCV than people without HIV infection [47]. HIV/HCV co-infection rates are particularly

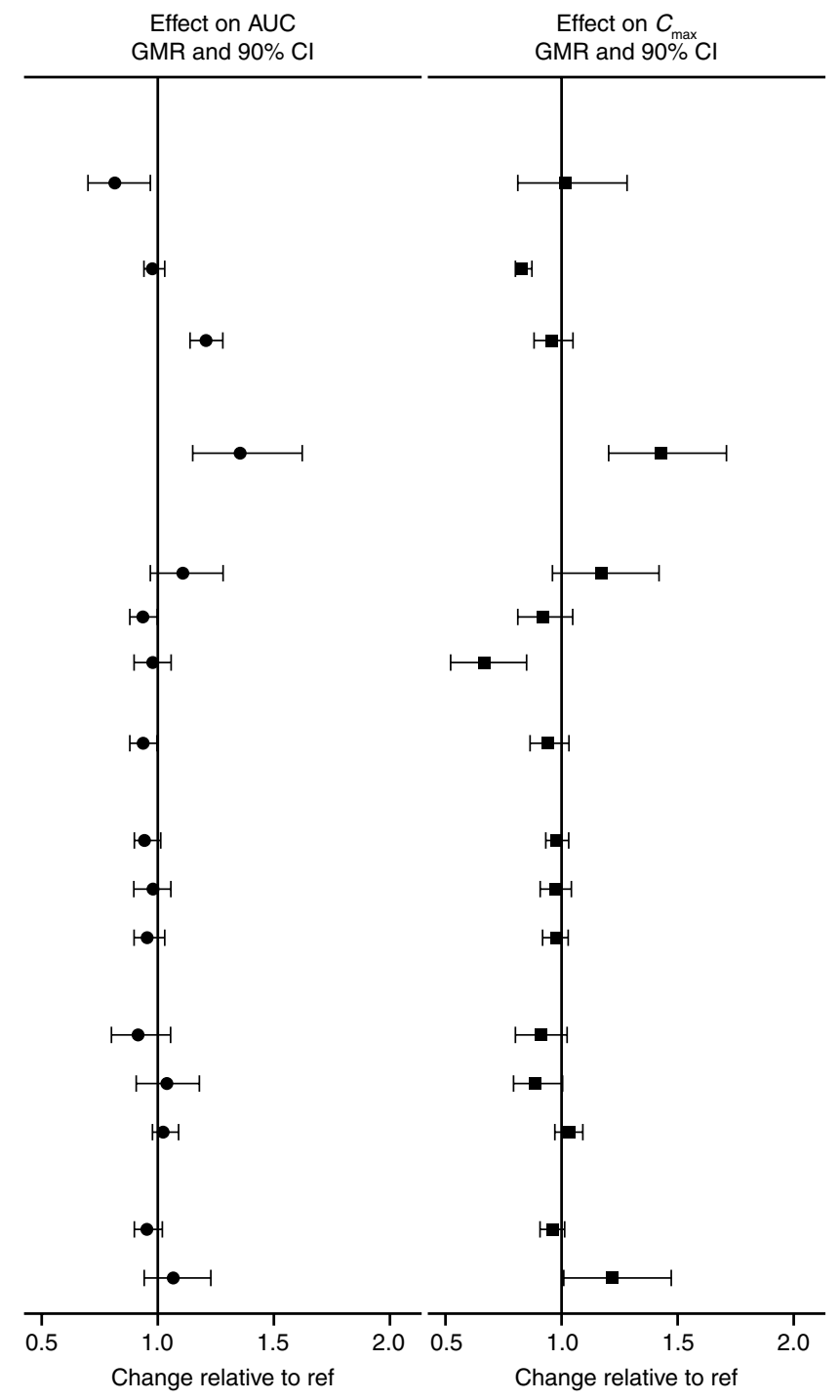

fidence interval, $D D I$ drug-drug interaction, $G M R$ geometric mean ratio, ref reference value, $S D$ single dose, $T D F$ tenofovir disoproxil fumarate

high in people who inject drugs; an estimated $82 \%$ of people living with HIV and who inject drugs are co-infected with HCV [47]. Consequently, co-administration of medications for these two viral infections is often required. The drug interaction potential following co-administration of doravirine with two anti-HCV treatments, elbasvir/grazoprevir and ledipasvir/sofosbuvir, has been evaluated [27]. Elbasvir and grazoprevir are CYP3A and P-gp substrates and grazoprevir is also a substrate for OATP1B1/B3. Elbasvir and grazoprevir are partially eliminated via CYP3A-mediated oxidative metabolism, and are primarily $(>90 \%)$ eliminated in feces [63]. Ledipasvir and sofosbuvir are P-gp and BCRP substrates [64]. Ledipasvir is eliminated primarily in 
feces as the unchanged drug (70\%), indicating that biliary excretion is the major route of elimination, while sofosbuvir is extensively metabolized in the liver to the active entity GS-461203, then eventually to the dephosphorylated metabolite GS331007. Renal clearance of GS-331007 is the main elimination pathway of sofosbuvir, accounting for $78 \%$ of the dose [64].

Increases in doravirine exposure following co-administration with either elbasvir/grazoprevir (56\%) or ledipasvir/ sofosbuvir (15\%) were observed (Table 2, Fig. 3), but were within the established clinical bounds for doravirine, and hence not considered to be clinically significant [27]. Grazoprevir, but not elbasvir, is a weak inhibitor of CYP3A [63]; thus, the observed modest increase in doravirine exposure is likely due to inhibition of CYP3A [27]. Small (10-25\%) increases in doravirine $\mathrm{AUC}_{0-\infty}, C_{24}$, and $C_{\max }$ seen following co-administration of ledipasvir/sofosbuvir with doravirine were thought to result from inhibition of P-gp by ledipasvir [64]; the high permeability of doravirine limits the effect of P-gp on its absorption [10], so that the effect of P-gp inhibitors on doravirine pharmacokinetics is small. Meanwhile, doravirine had no clinically meaningful effect on the pharmacokinetics of elbasvir, grazoprevir, ledipasvir, sofosbuvir, or the sofosbuvir metabolite GS-331007 (Tables 2 and 3, Fig. 4), which supports the limited effects of doravirine on the transporters involved in uptake of these drugs, despite doravirine being a known weak inhibitor of BCRP [27, 45]. Therefore, antiviral treatment of HIV/HCV co-infection with doravirine and elbasvir/grazoprevir or ledipasvir/sofosbuvir is a viable option [27].

Similarly, other anti-HCV direct-acting antivirals are anticipated to have minimal effect on doravirine pharmacokinetics. Several are known to be CYP3A4 substrates (e.g., ombitasvir, daclatasvir, paritaprevir, velpatasvir, voxilaprevir), or substrates and weak inhibitors (e.g., simeprevir, glecaprevir) [65]; based on other clinical trials of doravirine, clinically meaningful DDIs with doravirine are unlikely with substrates or inhibitors of CYP3A [26].

\subsection{Doravirine and Antifungal Agents}

Antifungal agents are vital for treating opportunistic infections that can occur in people living with HIV [66]. Ketoconazole is a broad-spectrum antifungal agent that is a strong CYP3A4 inhibitor [59, 67], a CYP3A4 substrate [68], and a potent inhibitor of UGT1A1 [67] and P-gp [69]. As expected, doravirine exposure was increased following co-administration of ketoconazole with doravirine compared with doravirine alone (Table 2, Fig. 3), likely due to reduced CYP3A-mediated clearance of doravirine following CYP3A4 inhibition by ketoconazole [26]. However, the $\sim 3$-fold increase in $\mathrm{AUC}_{0-\infty}$ was accompanied by only a $25 \%$ increase in $C_{\max }$, despite P-gp inhibition by ketoconazole, further supporting that the increased exposure of doravirine was due to decreased metabolism by CYP3A rather than P-gp inhibition [26]. Overall, the observed changes to doravirine pharmacokinetics were not considered clinically meaningful in the context of the clinical trial experience with doravirine [11, 26, 32]; therefore, co-administration of doravirine with ketoconazole or other strong CYP3A4 inhibitors is supported [26].

Like ketoconazole, several other azole antifungals are inhibitors of CYP3A4, including fluconazole, itraconazole, posaconazole, and voriconazole [70]. However, based on the finding above that ketoconazole, as a strong CYP3A4 inhibitor, does not lead to clinically meaningful changes in doravirine pharmacokinetics, co-administration of doravirine with other azoles will not necessitate dose adjustment $[8,9]$.

\subsection{Doravirine and Antimycobacterial Agents}

Tuberculosis remains the leading cause of death in people living with HIV [1]. The combination of antiretroviral and tuberculosis treatments has averted an estimated 9 million deaths from 2000 to 2016 [71]. Rifampin is a first-line agent for the initial treatment of tuberculosis in people living with HIV, taken in combination with isoniazid, ethambutol, and pyrazinamide [72]. As a strong CYP3A inducer [73], rifampin is known to have clinically significant DDIs with a number of antiretroviral drugs [72]. Consistent with the strong induction of CYP3A4 by rifampin, doravirine exposure was reduced by $88 \%$ and $C_{24}$ was reduced by $97 \%$ following co-administration with multiple-dose rifampin in healthy adult men (Table 2, Fig. 3), indicating that the efficacy of doravirine when co-administered with rifampin in individuals with HIV/tuberculosis co-infection would be substantially compromised [74]. As a result, co-administration of rifampin with doravirine is contraindicated $[8$, 9]. Rifabutin is another member of the rifamycin class of antimycobacterials but is a less potent CYP3A inducer than rifampin [73]. Doravirine exposure in healthy adults was also reduced following co-administration with rifabutin but to a lesser extent than with rifampin (50\% reduction; Table 2, Fig. 3) [75]. Based on projections from doravirine pharmacokinetics in the presence of rifabutin, the interaction is mitigated by increasing the doravirine dose from $100 \mathrm{mg}$ once daily to $100 \mathrm{mg}$ twice daily [75]. As such, dose adjustment of doravirine to $100 \mathrm{mg}$ twice daily is recommended for co-administration with rifabutin [8,9], allowing doravirine to be used in HIV/tuberculosis co-infection treatment.

The other components of first-line therapy for tuberculosis include isoniazid, ethambutol, and pyrazinamide. Isoniazid metabolism results mainly from the actions of $\mathrm{N}$-acetyltransferase 2 and amidase, and there is evidence of interactions with various CYPs, including inhibition of CYP3A4 [76, 77]. Ethambutol was shown to inhibit a 
number of CYPs but had only a weak inhibitory effect on CYP3A [78]. As no dose adjustment is required for the concomitant use of doravirine and strong CYP3A inhibitors [26], interactions between ethambutol or isoniazid and doravirine are not expected to be clinically meaningful. Pyrazinamide was shown to have no inhibitory effect on CYP enzymes, including CYP3A4 [77].

\subsection{Doravirine and Antidiabetic Drugs}

Type 2 diabetes mellitus is a common co-morbidity in people with HIV-1 infection [38]. Metformin is the recommended first-line therapy [79], and therefore concomitant administration with doravirine may be required. Co-administration of doravirine and metformin had no clinically meaningful effect on metformin pharmacokinetics (Table 3, Fig. 4) [29]. Metformin is excreted unchanged in urine [80] and therefore not dependent on CYP3A-mediated metabolism. The lack of interaction of doravirine with metformin demonstrates that it has no clinically meaningful effect on the transporters involved in uptake and transport of metformin in vivo [29]—namely PMAT, OCT1, OCT2, OCT3, MATE1, and MATE2 $\mathrm{K}[80,81]$ - and confirms in vitro findings that doravirine has low potential for interactions with OCT2 and MATE1/2K [45].

Overall, it is anticipated that doravirine has low potential for interaction with antidiabetic drugs. Most clinically meaningful DDIs of antidiabetic drugs result from inhibition or induction of hepatic CYPs [82]. Sulfonylureas are metabolized by various CYP enzymes, including CYP2C9 and CYP3A4 [82]. Due to a lack of modulation of these enzymes by doravirine, interactions are thought to be unlikely. In addition, these agents are not perpetrators of CYP3A-mediated DDIs, and therefore would not have a clinically meaningful effect on doravirine pharmacokinetics. It should be noted that glyburide is a weak inhibitor of CYP3A [83]; however, a clinically meaningful interaction with doravirine would not be anticipated. Dipeptidyl peptidase-4 inhibitors, with the exception of saxagliptin, have no known DDIs with commonly used concomitant medications [82]. Saxagliptin is a CYP3A4/5 substrate and may be affected by inducers and inhibitors. As with sulfonylureas, saxagliptin is unlikely to be affected by doravirine via this pathway. Sitagliptin and saxagliptin are not CYP3A inhibitors or inducers, and would therefore not be expected to affect the pharmacokinetics of doravirine $[84,85]$.

The sodium-glucose co-transporter (SGLT)-2 inhibitors ertugliflozin, empagliflozin, dapagliflozin, and canagliflozin undergo hepatic glucuronidation and are not cleared to a major extent by CYP enzymes [82]. Canagliflozin requires dose adjustment when co-administered with UGT inducers; however, no other clinically meaningful DDIs of SGLT-2 inhibitors have been identified [82]. Therefore, doravirine and SGLT-2 inhibitors can be co-administered without interactions. Pioglitazone and rosiglitazone, members of the thiazolidinedione drug class, are metabolized mainly via CYP2C8, with lesser contributions of CYP3A4 and CYP2C9 metabolism, respectively [82], and are therefore unlikely to be affected by doravirine. While doravirine is not expected to affect the metabolism of pioglitazone, pioglitazone is a weak CYP3A inducer [59], and therefore doravirine concentrations may potentially be slightly reduced with co-administration.

Doravirine is not anticipated to affect the pharmacokinetics of liraglutide, a subcutaneously administered glucagonlike peptide-1 (GLP1) receptor agonist, since liraglutide metabolism does not rely on a specific organ for elimination and is instead endogenously metabolized in a similar fashion to large proteins [86]. Liraglutide has been shown to alter absorption of concomitantly administered oral agents through delayed gastric emptying [86]. However, liraglutide did not affect the absorption of tested drugs to a clinically meaningful degree: AUC changes for digoxin, lisinopril, atorvastatin, acetaminophen, and ethinyl estradiol/levonorgestrel ranged from a decrease of $16 \%$ to an increase of $18 \%$ [86]. The effect of liraglutide on doravirine, a Biopharmaceutical Classification System Class II compound, is therefore not expected to be clinically meaningful.

\subsection{Doravirine and Statins}

The 3-hydroxy-3-methylglutaryl coenzyme A reductase inhibitors (statins) are used for the treatment of hypercholesterolemia, a common co-morbidity in individuals with HIV infection [87]. Doravirine had no clinically meaningful effect on atorvastatin pharmacokinetics following co-administration (Table 3, Fig. 4) [21]. Although the $C_{\max }$ of atorvastatin was decreased by $33 \%$ with co-administration, the difference was not considered clinically meaningful due to efficacy being demonstrated in the presence of other factors that caused similar atorvastatin pharmacokinetic changes $[21,88,89]$. These results indicated that doravirine does not meaningfully impact the activity of CYP3A4, OATP1B1, P-gp, or BCRP, for which atorvastatin is a substrate [21]. As simvastatin [90], pravastatin [91], rosuvastatin [92], and lovastatin [93] are also substrates for one or more of these pathways, doravirine is not anticipated to have a clinically meaningful effect on the pharmacokinetics of these statins. Additionally, fluvastatin [94] is also a substrate for CYP2C9 while pitavastatin is a substrate for OATP1B $1 / 3$ and primarily metabolized by UGT1A3 and UGT2B $7[95,96]$. As in vitro data support that doravirine is not a modulator of CYP2C9 and is unlikely to modulate UGT enzymes [45], doravirine is also not expected to affect the disposition of fluvastatin or pitavastatin. Furthermore, to the best of our knowledge, none of these statins are known to be clinically 
meaningful perpetrators of DDIs via CYP3A-mediated metabolism [59], and are therefore not expected to have a clinically meaningful effect on the pharmacokinetics of doravirine. Therefore, doravirine may be co-administered with atorvastatin, fluvastatin, lovastatin, pravastatin, pitavastatin, or simvastatin, without dose adjustment of doravirine or any of these statins.

\subsection{Doravirine and Opioid Substitution Therapies}

Injection drug use was responsible for $\sim 6 \%$ of new diagnoses of HIV infection in the USA in 2016 [97], and $2.1 \%$ of people living with HIV in the USA reported recent opiate use in a 2013 study [98]. Methadone, an opioid substitution therapy widely used to treat opioid addiction [99], is often co-administered with HIV antiretroviral therapy [100]. Potential interactions between methadone and doravirine were investigated in individuals participating in a methadone maintenance program. Methadone pharmacokinetics (for $(R)_{-},(S)$-, and total methadone) were not meaningfully affected with doravirine co-administration (Table 3 , Fig. 4) [30]. Comparison with data from a previous trial in participants receiving doravirine without methadone coadministration [15] revealed that doravirine exposure was modestly reduced by $26 \%$ following co-administration with methadone (Table 2, Fig. 3). The mechanism for this reduction is not clear, although it was suggested that reduced gut motility limiting doravirine absorption may be responsible [30]. However, the changes were not considered clinically meaningful on the basis of the established clinical bounds for doravirine [30].

Another treatment for opioid dependence is buprenorphine/naloxone [101]. CYP3A is important in the metabolism of buprenorphine but would not be affected by coadministration of doravirine, and naloxone does not undergo CYP-mediated metabolism. While buprenorphine is a CYP3A4 and CYP2D6 inhibitor in vitro, DDIs are not a concern as therapeutic concentrations are expected to be too low to perpetrate clinically meaningful DDIs [101]. Therefore, doravirine and buprenorphine/naloxone may be co-administered without dose adjustment.

\subsection{Doravirine and Oral Contraceptives}

The use of hormonal contraceptives is anticipated in the doravirine target population. Ethinyl estradiol $0.03 \mathrm{mg} / \mathrm{lev}-$ onorgestrel $0.15 \mathrm{mg}$ is a fixed-dose oral contraceptive [102] and both components are CYP3A substrates [103, 104]. No clinically meaningful changes to the pharmacokinetics of ethinyl estradiol or levonorgestrel were observed following co-administration with doravirine (Table 3, Fig. 4). Although levonorgestrel $\mathrm{AUC}_{0-\infty}$ was slightly elevated, this increase was not considered clinically meaningful on the basis of levonorgestrel exposures observed in other marketed contraceptives containing the same dose of levonorgestrel [26]. Hence, it was concluded that dose adjustment of ethinyl estradiol and levonorgestrel are not required for co-administration with doravirine [26].

\subsection{Doravirine and Antacids}

Gastric acid-reducing agents are commonly used by people living with HIV-1 [105]. However, some antiretroviral drugs are restricted or contraindicated for use with such agents due to impaired absorption leading to reductions in plasma concentrations of the anti-HIV drugs [3]. Co-administration of either an aluminum-/magnesium-containing antacid or the proton-pump inhibitor pantoprazole with doravirine did not have a clinically meaningful effect on doravirine pharmacokinetics (Table 2, Fig. 3) [28]. Slight decreases (12-17\%) in doravirine $\mathrm{AUC}_{0-\infty}, C_{\max }$, and $C_{24}$ following co-administration with pantoprazole, and in doravirine $C_{\max }$ following co-administration with an antacid, were not considered clinically meaningful on the basis of the established clinical bounds for doravirine. Gastric acid-reducing agents may be co-administered with doravirine without need for dose adjustments or restrictions [28].

\section{Clinical Perspective}

The population living with HIV is clinically and demographically diverse and has changed over time [1, 34, 38]. The presence of co-morbidities has increased in recent years [38], and with it comes the likelihood of polypharmacy and potential for DDIs with antiretroviral drugs [46]. The success of antiretroviral therapy has led to improvements in life expectancy, resulting in an aging population living with HIV [34]. Chronic kidney disease [41], hepatic disease [39], and cardiovascular disease [38] are complications commonly experienced by people living with HIV, so consideration of these populations may be particularly important. Doravirine is a novel NNRTI that has pharmacokinetic properties that support once-daily administration and address the complex HIV patient population needs. The clinical trials and population pharmacokinetic analysis described here support the use of doravirine across a wide range of populations with HIV-1 infection: age, gender, race, ethnicity, weight/BMI, renal function, and moderate hepatic impairment did not have an appreciable effect on doravirine pharmacokinetics, nor did food (fed or fasted) have a clinically meaningful impact [14, 22-25].

Doravirine was shown to have limited potential for clinically meaningful DDIs based on data obtained from in vitro studies of drug-metabolizing enzymes and drug transporters [10, 45] and clinical studies [15, 20, 21, 26-31]. Since 
doravirine is a substrate of CYP3A4 [10], the most likely route of its involvement in DDIs is via inhibition and induction of CYP3A activity by strong and moderate CYP3A inhibitors/inducers. CYP3A inhibition does not result in a clinically meaningful change in doravirine pharmacokinetics, and doravirine can be co-administered with these agents without dose adjustment. However, moderate and strong CYP3A inducers reduced doravirine exposure. For strong inducers, the magnitude of the decrease may impact efficacy; therefore, doravirine is contraindicated for use with any strong CYP3A inducer (e.g., rifampin, mitotane, avasimibe, phenytoin, carbamazepine, and enzalutamide) [8, $9,74]$. Similar restrictions for rifampin are also in place for other antiretroviral medications, including all PIs and several NNRTIs (including etravirine, nevirapine, and rilpivirine) [3]. TAF and cobicistat-boosted elvitegravir are contraindicated for both rifampin and rifabutin [3]. Dose adjustment of doravirine is recommended for the moderate inducer rifabutin [75]. As the magnitude of induction associated with CYP3A moderate inducers varies across compounds (e.g., etravirine, nevirapine, bosentan, nafcillin, and modafinil), and is also dependent on the substrate, the effect of other moderate inducers on the pharmacokinetics of doravirine cannot easily be predicted. However, if co-administration with moderate inducers cannot be avoided, doravirine dosing frequency should be increased from $100 \mathrm{mg}$ once daily to $100 \mathrm{mg}$ twice daily. A fixed-dose combination of doravirine with $3 \mathrm{TC}$ and TDF at the recommended adult doses of $100 \mathrm{mg}$ doravirine and $300 \mathrm{mg}$ each of 3TC and TDF is also available [9]. While the pharmacokinetic characteristics of doravirine support the administration of $100 \mathrm{mg}$ doravirine with minimal restrictions due to intrinsic factors and DDIs, dose recommendations for the fixed-dose combination may be influenced by the effect of intrinsic factors, such as renal impairment, on the pharmacokinetic profiles of 3TC and/ or TDF, which are primarily renally cleared [9]. The use of TDF has also been associated with the onset or worsening of renal impairment in some patients [9]. Additionally, drug interactions specific to 3TC or TDF may also result in recommendations of additional monitoring for AEs related to increases in concentration of the 3TC or TDF component, as in the case of co-administration of the fixed-dose combination with ledipasvir/sofosbuvir [9].

The collective data demonstrate that the overall DDI profile of doravirine allows the co-administration of doravirine with a diverse range of concomitant medications and may offer advantages over existing antiretroviral therapies. For example, several boosted PIs, including ritonavir-boosted atazanavir, ritonavir-boosted darunavir, and ritonavirboosted lopinavir, are contraindicated with elbasvir/grazoprevir due to OATP1B1/3 inhibition leading to increased plasma grazoprevir concentrations [3]; efavirenz and etravirine/nevirapine are also contraindicated with elbasvir/ grazoprevir due to the resulting decrease in elbasvir and grazoprevir exposures, and ritonavir-boosted tipranavir is expected to reduce ledipasvir and sofosbuvir concentrations [3]. Rilpivirine is contraindicated with proton-pump inhibitors, and raltegravir should not be co-administered with aluminum-/magnesium-containing hydroxide antacids [3]. Meanwhile, care must be taken when co-administering cobicistat-boosted elvitegravir with atorvastatin, and dolutegravir with metformin [3]. The broad suitability of doravirine in the presence of concomitant medications therefore offers freedom from some of the restrictions associated with other antiretroviral regimens and provides additional flexibility in managing polypharmacy. Similar conclusions have been drawn by other authors [106, 107].

As doravirine will be co-administered with other antiretroviral agents, the favorable drug-interaction profile supports the combination of doravirine with the most commonly used drugs, including 3TC and TDF [31]. These results contrast with the alterations in pharmacokinetics seen with other agents. For example, when TDF is co-administered with ritonavir-boosted atazanavir, decreased atazanavir exposure occurred [108]. Switching from a PI-, NNRTI-, or InSTIbased regimen to a doravirine-based regimen is also an important consideration. Phase III results supported a switch from commonly used regimens to doravirine [54], and thus doravirine has been approved to replace the current antiretroviral therapy in appropriate patients who are virologically suppressed on their current regimen $[8,9]$. Based on drug interaction properties of other antiretroviral agents, this ease of switch may not be feasible for other drugs.

While it should be taken into consideration that data to date have been generated either under strictly controlled phase I trial conditions or in well-controlled phase II and phase III trials, which began to emulate real-world conditions but still included several restrictions for inclusion and exclusion, the safety, tolerability, and efficacy profile of doravirine is expected to evolve with its expanded use in clinical settings as a greater number of patients with comorbidities and polypharmacy are treated with doravirinebased regimens. However, given the overall pharmacokinetic profile of doravirine and the benefits it brings compared with existing treatment options, it is expected that doravirine has the potential to become a valuable addition to the available treatments for HIV-1 infection across a diverse range of populations living with HIV.

\section{Conclusions}

In summary, evaluation of published clinical pharmacokinetics trials of doravirine demonstrates a low potential for DDIs with doravirine and limited impact of patient characteristics. Although doravirine is contraindicated for co-administration 
with strong CYP3A inducers and requires dose adjustment for co-administration with the moderate CYP3A inducer rifabutin, DDIs with other drugs are unlikely. As a result, its pharmacological profile makes doravirine a potential treatment option for a broad range of people living with HIV, including older populations and those with co-morbidities requiring the use of concomitant medications.

Acknowledgements Medical writing assistance, under the direction of the authors, was provided by Kirsty Muirhead, PhD, of CMC AFFINITY, McCann Health Medical Communications, in accordance with Good Publication Practice (GPP3) guidelines. This assistance was funded by Merck Sharp \& Dohme Corp., a subsidiary of Merck \& Co., Inc., Kenilworth, NJ, USA.

Author Contributions MI, SK, SAS, and KLY designed the research. MI, SK, RS, SAS, LW. and KLY analyzed/interpreted the data. MI, SK, RS, SAS, LW, and KLY wrote or revised the manuscript.

\section{Compliance with Ethical Standards}

Funding Funding for this research was provided by Merck Sharp \& Dohme Corp., a subsidiary of Merck \& Co., Inc., Kenilworth, NJ, USA. Medical writing assistance was funded by Merck Sharp \& Dohme Corp., a subsidiary of Merck \& Co., Inc., Kenilworth, NJ, USA.

Conflict of interest/competing interests SK, KLY, RS, SAS, LW, and MI are current employees of Merck Sharp \& Dohme Corp., a subsidiary of Merck \& Co., Inc., Kenilworth, NJ, USA, and may own stock and/or hold stock options in the Merck \& Co., Inc., Kenilworth, NJ, USA.

Open Access This article is licensed under a Creative Commons Attribution-NonCommercial 4.0 International License, which permits any non-commercial use, sharing, adaptation, distribution and reproduction in any medium or format, as long as you give appropriate credit to the original author(s) and the source, provide a link to the Creative Commons licence, and indicate if changes were made. The images or other third party material in this article are included in the article's Creative Commons licence, unless indicated otherwise in a credit line to the material. If material is not included in the article's Creative Commons licence and your intended use is not permitted by statutory regulation or exceeds the permitted use, you will need to obtain permission directly from the copyright holder. To view a copy of this licence, visit http://creativecommons.org/licenses/by-nc/4.0/.

\section{References}

1. UNAIDS. Global HIV \& AIDS statistics-2019 fact sheet. 2019. http://www.unaids.org/en/resources/fact-sheet. Accessed 19 Aug 2019.

2. European AIDS Clinical Society. European guidelines for treatment of HIV-positive adults in Europe, version 9.1. http://www. eacsociety.org/files/2018_guidelines-9.1-english.pdf. Accessed 14 May 2019.

3. Panel on Antiretroviral Guidelines for Adults and Adolescents. Guidelines for the Use of Antiretroviral Agents in Adults and Adolescents Living with HIV. 2018. https://aidsinfo.nih.gov/ contentfiles/lvguidelines/adultandadolescentgl.pdf. Accessed 19 Aug 2019.
4. Orkin C, Squires KE, Molina JM, Sax PE, Wong WW, Sussmann $\mathrm{O}$, et al. Doravirine/lamivudine/tenofovir disoproxil fumarate is non-inferior to efavirenz/emtricitabine/tenofovir disoproxil fumarate in treatment-naive adults with human immunodeficiency virus-1 infection: week 48 results of the DRIVE-AHEAD trial. Clin Infect Dis. 2019;68:535-44.

5. Molina JM, Squires K, Sax PE, Cahn P, Lombaard J, DeJesus E, et al. Doravirine versus ritonavir-boosted darunavir in antiretroviral-naive adults with HIV-1 (DRIVE-FORWARD): 48-week results of a randomised, double-blind, phase 3, non-inferiority trial. Lancet HIV. 2018;5:e211-20.

6. Feng M, Sachs NA, Xu M, Grobler J, Blair W, Hazuda DJ, et al. Doravirine suppresses common nonnucleoside reverse transcriptase inhibitor-associated mutants at clinically relevant concentrations. Antimicrob Agents Chemother. 2016;60:2241-7.

7. Feng M, Wang D, Grobler JA, Hazuda DJ, Miller MD, Lai M-T. In vitro resistance selection with doravirine (MK-1439), a novel nonnucleoside reverse transcriptase inhibitor with distinct mutation development pathways. Antimicrob Agents Chemother. 2015;59:590-8.

8. Merck Sharp \& Dohme Corp. PIFELTRO ${ }^{\mathrm{TM}}$ (doravirine) Prescribing Information. Merck \& Co., Inc., Whitehouse Station, NJ, USA. https://www.merck.com/product/usa/pi_circulars/p/ pifeltro/pifeltro_pi.pdf. Accessed 14 May 2020.

9. Merck Sharp \& Dohme Corp. DELSTRIGO ${ }^{\mathrm{TM}}$ (doravirine, lamivudine, and tenofovir disoproxil fumarate) Prescribing Information. Merck \& Co., Inc., Whitehouse Station, NJ, USA. https ://www.merck.com/product/usa/pi_circulars/d/delstrigo/delst rigo_pi.pdf. Accessed 14 May 2020.

10. Sanchez RI, Fillgrove KL, Yee KL, Liang Y, Lu B, Tatavarti A, et al. Characterisation of the absorption, distribution, metabolism, excretion and mass balance of doravirine, a non-nucleoside reverse transcriptase inhibitor in humans. Xenobiotica. 2019;49:422-32.

11. Anderson MS, Gilmartin J, Cilissen C, De Lepeleire I, van Bortel L, Dockendorf MF, et al. Safety, tolerability and pharmacokinetics of doravirine, a novel HIV non-nucleoside reverse transcriptase inhibitor, after single and multiple doses in healthy subjects. Antivir Ther. 2015;20:397-405.

12. Wang X, Milinkovic A, Pereira B, Moyle G, Fedele S, Thomas L, et al. Pharmacokinetics of once-daily doravirine over $72 \mathrm{~h}$ following drug cessation. J Antimicrob Chemother. 2020;75(6):1658-60.

13. Schürmann D, Sobotha C, Gilmartin J, Robberechts M, De Lepeleire I, Yee KL, et al. A randomized, double-blind, placebo-controlled, short-term monotherapy study of doravirine in treatmentnaive HIV-infected individuals. AIDS. 2016;30:57-63.

14. Yee KL, Ouerdani A, Claussen A, de Greef R, Wenning L. Population pharmacokinetics of doravirine and exposure-response in individuals with HIV-1. Antimicrob Agents Chemother. 2019;63:e2502-18.

15. Yee KL, Sanchez RI, Auger P, Liu R, Fan L, Triantafyllou I, et al. Evaluation of doravirine pharmacokinetics when switching from efavirenz to doravirine in healthy subjects. Antimicrob Agents Chemother. 2017;61:e01757-16.

16. Xu Y, Li YF, Zhang D, Dockendorf M, Tetteh E, Rizk ML, et al. Characterizing class-specific exposure-viral load suppression response of HIV antiretrovirals using a model-based meta-analysis. Clin Transl Sci. 2016;9:192-200.

17. Gatell JM, Morales-Ramirez JO, Hagins DP, Thompson M, Arasteh K, Hoffmann C, et al. Doravirine dose selection and 96-week safety and efficacy versus efavirenz in antiretroviral therapy-naive adults with HIV-1 infection in a Phase IIb trial. Antivir Ther. 2019;24:425-35.

18. Cote B, Burch JD, Asante-Appiah E, Bayly C, Bedard L, Blouin M, et al. Discovery of MK-1439, an orally bioavailable 
non-nucleoside reverse transcriptase inhibitor potent against a wide range of resistant mutant HIV viruses. Bioorg Med Chem Lett. 2014;24:917-22.

19. Lai MT, Feng M, Falgueyret JP, Tawa P, Witmer M, DiStefano D, et al. In vitro characterization of MK-1439, a novel HIV-1 nonnucleoside reverse transcriptase inhibitor. Antimicrob Agents Chemother. 2014;58:1652-63.

20. Anderson MS, Khalilieh S, Yee KL, Liu R, Fan L, Rizk ML, et al. A two-way steady-state pharmacokinetic interaction study of doravirine (MK-1439) and dolutegravir. Clin Pharmacokinet. 2017;56:661-9.

21. Khalilieh S, Yee KL, Sanchez RI, Triantafyllou I, Fan L, Maklad $\mathrm{N}$, et al. Results of a doravirine-atorvastatin drug-drug interaction study. Antimicrob Agents Chemother. 2017;61:e01364-16.

22. Behm MO, Yee KL, Fan L, Fackler P. Effect of gender and age on the relative bioavailability of doravirine: results of a Phase I trial in healthy subjects. Antivir Ther. 2017;22:337-44.

23. Behm MO, Yee KL, Liu R, Levine V, Panebianco D, Fackler P. The effect of food on doravirine bioavailability: results from two pharmacokinetic studies in healthy subjects. Clin Drug Investig. 2017;37:571-9.

24. Ankrom W, Yee KL, Sanchez RI, Adedoyin A, Fan L, Marbury $\mathrm{T}$, et al. Severe renal impairment has minimal impact on doravirine pharmacokinetics. Antimicrob Agents Chemother. 2018;62:e0326-18.

25. Khalilieh S, Yee KL, Liu R, Fan L, Sanchez RI, Auger P, et al. Moderate hepatic impairment does not affect doravirine pharmacokinetics. J Clin Pharmacol. 2017;57:777-83.

26. Khalilieh SG, Yee KL, Sanchez RI, Fan L, Anderson MS, Sura M, et al. Doravirine and the potential for CYP3A-mediated drug-drug interactions. Antimicrob Agents Chemother. 2019;63:e02016-18.

27. Ankrom W, Sanchez RI, Yee KL, Fan L, Mitra P, Wolford D, et al. Investigation of pharmacokinetic interactions between doravirine and elbasvir/grazoprevir and ledipasvir/sofosbuvir. Antimicrob Agents Chemother. 2019;63:e02491-18.

28. Khalilieh SG, Yee KL, Sanchez RI, Fan L, Vaynshteyn K, Deschamps K, et al. A study to evaluate doravirine pharmacokinetics when coadministered with acid-reducing agents. J Clin Pharmacol. 2019;59:1093-8.

29. Sanchez RI, Yee KL, Fan L, Cislak D, Martell M, Jordan HR, et al. Evaluation of the pharmacokinetics of metformin following coadministration with doravirine in healthy volunteers. Clin Pharmacol Drug Dev. 2020;9:107-14.

30. Khalilieh S, Yee KL, Sanchez RI, Vaynshteyn K, Fan L, Searle $\mathrm{S}$, et al. Evaluation of the pharmacokinetic interaction between doravirine and methadone. Clin Pharmacol Drug Dev. 2019;9:151-61.

31. Anderson MS, Gilmartin J, Fan L, Yee KL, Kraft WK, Triantafyllou I, et al. No meaningful drug interactions with doravirine, lamivudine and tenofovir disoproxil fumarate co-administration. Antivir Ther. 2019;24:443-50.

32. Khalilieh SG, Yee KL, Fan L, Liu R, Heber W, Dunzo E, et al. A randomized trial to assess the effect of doravirine on the QTc interval using a single supratherapeutic dose in healthy adult volunteers. Clin Drug Investig. 2017;37:975-84

33. Mangoni AA, Jackson SH. Age-related changes in pharmacokinetics and pharmacodynamics: basic principles and practical applications. Br J Clin Pharmacol. 2004;57:6-14.

34. Sabin CA, Reiss P. Epidemiology of ageing with HIV: what can we learn from cohorts? AIDS. 2017;31(Suppl 2):S121-8.

35. Courlet P, Stader F, Guidi M, Alves Saldanha S, Stoeckle M, Cavassini M, et al. Pharmacokinetic profiles of boosted darunavir, dolutegravir and lamivudine in aging people living with HIV. Aids. 2020;34:103-8.
36. Soldin OP, Mattison DR. Sex differences in pharmacokinetics and pharmacodynamics. Clin Pharmacokinet. 2009;48:143-57.

37. Hu Z-Y, Zhao Y-S. Sex-dependent differences in cytochrome P450 3A activity as assessed by midazolam disposition in humans: a meta-analysis. Drug Metab Dispos. 2010;38:817-23.

38. Gallant J, Hsue PY, Shreay S, Meyer N. Comorbidities among US patients with prevalent HIV infection-a trend analysis. J Infect Dis. 2017;216:1525-33.

39. Price JC, Thio CL. Liver disease in the HIV-infected individual. Clin Gastroenterol Hepatol. 2010;8:1002-12.

40. Verbeeck RK. Pharmacokinetics and dosage adjustment in patients with hepatic dysfunction. Eur J Clin Pharmacol. 2008;64:1147-61.

41. Naicker S, Rahmanian S, Kopp JB. HIV and chronic kidney disease. Clin Nephrol. 2015;83:S32-8.

42. Ladda MA, Goralski KB. The effects of CKD on cytochrome P450-mediated drug metabolism. Adv Chronic Kidney Dis. 2016;23:67-75.

43. Food and Drug Administration (FDA). Full prescribing information: INTELENCETM (etravirine). 2018. https://www.acces sdata.fda.gov/drugsatfda_docs/label/2018/022187s023lbl.pdf. Accessed 29 Apr 2019.

44. Janssen Therapeutics. EDURANT ${ }^{\circledR}$ (rilpivirine) prescribing information. 2018. http://www.janssenlabels.com/package-insert/ product-monograph/prescribing-information/EDURANT-pi.pdf. Accessed 23 May 2018.

45. Bleasby K, Fillgrove KL, Houle R, Lu B, Palamanda J, Newton DJ, et al. In vitro evaluation of the drug interaction potential of doravirine. Antimicrob Agents Chemother. 2019;63:e2492-18.

46. Tseng A, Szadkowski L, Walmsley S, Salit I, Raboud J. Association of age with polypharmacy and risk of drug interactions with antiretroviral medications in HIV-positive patients. Ann Pharmacother. 2013;47:1429-39.

47. Platt L, Easterbrook P, Gower E, McDonald B, Sabin K, McGowan C, et al. Prevalence and burden of HCV co-infection in people living with HIV: a global systematic review and metaanalysis. Lancet Infect Dis. 2016;16:797-808.

48. GlaxoSmithKline/ViiV Healthcare. EPIVIR (lamivudine) prescribing information. 2019. https://www.gsksource.com/pharm a/content/dam/GlaxoSmithKline/US/en/Prescribing_Informatio n/Epivir/pdf/EPIVIR-PI-PIL.PDF. Accessed 19 Aug 2019.

49. Gilead Sciences, Inc. VIREAD ${ }^{\circledR}$ (tenofovir disoproxil fumarate) Prescribing Information. 2018. http://www.gilead.com/ / media/Files/pdfs/medicines/liver-disease/viread/viread_pi.pdf. Accessed 19 Aug 2019.

50. Gilead Sciences, Inc. VEMLIDY ${ }^{\circledR}$ (tenofovir alafenamide) prescribing information. 2018. https://www.gilead.com/ /media /files/pdfs/medicines/liver-disease/vemlidy/vemlidy_pi.pdf. Accessed 22 Oct 2018.

51. Bristol-Myers Squibb Co. Sustiva ${ }^{\circledR}$ (efavirenz) prescribing information. 2019. https://packageinserts.bms.com/pi/pi_sustiva.pdf. Accessed 26 Feb 2020.

52. Mouly S, Lown KS, Kornhauser D, Joseph JL, Fiske WD, Benedek IH, et al. Hepatic but not intestinal CYP3A4 displays dose-dependent induction by efavirenz in humans. Clin Pharmacol Ther. 2002;72:1-9.

53. Marzolini C, Telenti A, Decosterd LA, Greub G, Biollaz J, Buclin T. Efavirenz plasma levels can predict treatment failure and central nervous system side effects in HIV-1-infected patients. AIDS. 2001;15:71-5.

54. Johnson M, Kumar P, Molina J-M, Rizzardini G, Cahn P, Bickel $\mathrm{M}$, et al. Switching to doravirine/lamivudine/tenofovir disoproxil fumarate (DOR/3TC/TDF) maintains HIV-1 virologic suppression through 48 weeks: results of the DRIVE-SHIFT Trial. J Acquir Immune Defic Syndr. 2019;81:463-72. 
55. Greaves W, Wan H, Yee KL, Kandala B, Vaddady P, Hwang C. Doravirine exposure and HIV-1 suppression after switching from an efavirenz-based regimen to doravirine/lamivudine/tenofovir disoproxil fumarate. Antimicrob Agents Chemother. 2019. 63:e01298-19.

56. Boehringer Ingelheim Pharmaceuticals Inc. VIRAMUNE ${ }^{\circledR}$ (nevirapine) prescribing information. 2018. https://docs.boehr inger-ingelheim.com/Prescribing\%20Information/PIs/Viramune/ Viramune.pdf. Accessed 23 Oct 2018.

57. Sevrioukova IF, Poulos TL. Structure and mechanism of the complex between cytochrome P4503A4 and ritonavir. Proc Natl Acad Sci USA. 2010;107:18422-7.

58. Gilead Sciences, Inc. TYBOST ${ }^{\circledR}$ (cobicistat) prescribing information. 2018. http://www.gilead.com/ /media/files/pdfs/medic ines/hiv/tybost/tybost_pi.pdf. Accessed 23 Oct 2018.

59. University of Washington. Drug Interaction Database Program. 2018. https://www.druginteractioninfo.org/. Accessed 20 Jan 2020.

60. Katlama C, Assoumou L, Valantin MA, Soulié C, Martinez E, Béniguel L, et al. Dual therapy combining raltegravir with etravirine maintains a high level of viral suppression over 96 weeks in long-term experienced HIV-infected individuals over 45 years on a PI-based regimen: results from the Phase II ANRS 163 ETRAL study. J Antimicrob Chemother. 2019;74:2742-51.

61. Reese MJ, Savina PM, Generaux GT, Tracey H, Humphreys JE, Kanaoka E, et al. In vitro investigations into the roles of drug transporters and metabolizing enzymes in the disposition and drug interactions of dolutegravir, a HIV integrase inhibitor. Drug Metab Dispos. 2013;41:353-61.

62. Min S, Song I, Borland J, Chen S, Lou Y, Fujiwara T, et al. Pharmacokinetics and safety of S/GSK1349572, a next-generation HIV integrase inhibitor, in healthy volunteers. Antimicrob Agents Chemother. 2010;54:254-8.

63. Merck Sharp \& Dohme Corp. ZEPATIER ${ }^{\circledR}$ (elbasvir/grazoprevir) prescribing information. Merck \& Co., Inc., Whitehouse Station, NJ, USA. 2017. http://www.merck.com/product/usa/pi_circu lars/z/zepatier/zepatier_pi.pdf. Accessed 24 May 2019.

64. Gilead Sciences, Inc. HARVONI ${ }^{\circledR}$ (ledipasvir/sofosbuvir) prescribing information. 2017. http://www.gilead.com/ /media/files /pdfs/medicines/liver-disease/harvoni/harvoni_pi.pdf. Accessed 24 May 2019.

65. Garrison KL, German P, Mogalian E, Mathias A. The drugdrug interaction potential of antiviral agents for the treatment of chronic hepatitis C infection. Drug Metab Dispos. 2018;46:1212-25.

66. Limper AH, Adenis A, Le T, Harrison TS. Fungal infections in HIV/AIDS. Lancet Infect Dis. 2017;17:e334-43.

67. Yong WP, Ramirez J, Innocenti F, Ratain MJ. Effects of ketoconazole on glucuronidation by UDP-glucuronosyltransferase enzymes. Clin Cancer Res. 2005;11:6699-704.

68. Janssen Pharmaceuticals. NIZORAL (ketoconazole) prescribing information. 2013. https://www.accessdata.fda.gov/drugsatfda _docs/label/2013/018533s040lbl.pdf. Accessed 3 Sep 2018.

69. Wang EJ, Lew K, Casciano CN, Clement RP, Johnson WW. Interaction of common azole antifungals with $\mathrm{P}$ glycoprotein. Antimicrob Agents Chemother. 2002;46:160-5.

70. Bellmann R, Smuszkiewicz P. Pharmacokinetics of antifungal drugs: practical implications for optimized treatment of patients. Infection. 2017;45:737-79.

71. World Health Organization. Global tuberculosis report 2017. Geneva, Switzerland; 2017. http://www.who.int/tb/publicatio ns/global_report/en/. Accessed 20 Jan 2020.

72. Panel on Opportunistic Infections in HIV-Infected Adults and Adolescents. Guidelines for the prevention and treatment of opportunistic infections in HIV-infected adults and adolescents: recommendations from the Centers for Disease Control and
Prevention, the National Institutes of Health, and the HIV Medicine Association of the Infectious Diseases Society of America. 2018. https://aidsinfo.nih.gov/contentfiles/lvguidelines/adult _oi.pdf. Accessed 10 Sep 2018.

73. Williamson B, Dooley KE, Zhang Y, Back DJ, Owen A. Induction of influx and efflux transporters and cytochrome P450 3A4 in primary human hepatocytes by rifampin, rifabutin, and rifapentine. Antimicrob Agents Chemother. 2013;57:6366-9.

74. Yee KL, Khalilieh SG, Sanchez RI, Liu R, Anderson MS, Manthos $\mathrm{H}$, et al. The effect of single and multiple doses of rifampin on the pharmacokinetics of doravirine in healthy subjects. Clin Drug Investig. 2017;37:659-67.

75. Khalilieh SG, Yee KL, Sanchez RI, Liu R, Fan L, Martell M, et al. Multiple doses of rifabutin reduce exposure of doravirine in healthy subjects. J Clin Pharmacol. 2018;58:1044-52.

76. Wang P, Pradhan K, Zhong XB, Ma X. Isoniazid metabolism and hepatotoxicity. Acta Pharm Sin B. 2016;6:384-92.

77. Nishimura Y, Kurata N, Sakurai E, Yasuhara H. Inhibitory effect of antituberculosis drugs on human cytochrome P450-mediated activities. J Pharmacol Sci. 2004;96:293-300.

78. Lee SY, Jang H, Lee JY, Kwon KI, Oh SJ, Kim SK. Inhibition of cytochrome $\mathrm{P} 450$ by ethambutol in human liver microsomes. Toxicol Lett. 2014;229:33-40.

79. American Diabetes Association. 8. Pharmacologic approaches to glycemic treatment: standards of medical care in diabetes-2018. Diabetes Care. 2018;2018(41):S73-85.

80. Gong L, Goswami S, Giacomini KM, Altman RB, Klein TE. Metformin pathways: pharmacokinetics and pharmacodynamics. Pharmacogenet Genomics. 2012;22:820-7.

81. Graham GG, Punt J, Arora M, Day RO, Doogue MP, Duong JK, et al. Clinical pharmacokinetics of metformin. Clin Pharmacokinet. 2011;50:81-98.

82. May M, Schindler C. Clinically and pharmacologically relevant interactions of antidiabetic drugs. Ther Adv Endocrinol Metab. 2016;7:69-83.

83. Kim KA, Park JY. Inhibitory effect of glyburide on human cytochrome $\mathrm{p} 450$ isoforms in human liver microsomes. Drug Metab Dispos. 2003;31:1090-2.

84. Merck Sharp \& Dohme Corp. JANUVIA ${ }^{\circledR}$ (sitagliptin) prescribing information. 2018. https://www.merck.com/product/usa/ pi_circulars/j/januvia/januvia_pi.pdf. Accessed 24 Oct 2018.

85. AstraZeneca. ONGLYZA ${ }^{\circledR}$ (saxagliptin) prescribing information. 2018. https://www.azpicentral.com/onglyza/pi_onglyza.pdf. Accessed 23 Oct 2018.

86. Novo Nordisk. VICTOZA ${ }^{\circledR}$ (liraglutide) prescribing information. 2017. https://www.accessdata.fda.gov/drugsatfda_docs/ label/2017/022341s027lbl.pdf. Accessed 24 Oct 2018.

87. Husain NE, Ahmed MH. Managing dyslipidemia in HIV/ AIDS patients: challenges and solutions. HIV AIDS (Auckl). 2014;7:1-10.

88. Whitfield LR, Stern RH, Sedman AJ, Abel R, Gibson DM. Effect of food on the pharmacodynamics and pharmacokinetics of atorvastatin, an inhibitor of HMG-CoA reductase. Eur J Drug Metab Pharmacokinet. 2000;25:97-101.

89. Cilla DD Jr, Gibson DM, Whitfield LR, Sedman AJ. Pharmacodynamic effects and pharmacokinetics of atorvastatin after administration to normocholesterolemic subjects in the morning and evening. J Clin Pharmacol. 1996;36:604-9.

90. Merck Sharp \& Dohme Corp. ZOCOR (simvastatin) prescribing information. 2018. https://www.merck.com/product/usa/pi_circu lars/z/zocor/zocor_pi.pdf. Accessed 24 Oct 2018.

91. Kivistö KT, Niemi M. Influence of drug transporter polymorphisms on pravastatin pharmacokinetics in humans. Pharm Res. 2007;24:239-47. 
92. AstraZeneca. CRESTOR (rosuvastatin calcium) prescribing information. 2018. https://www.azpicentral.com/crestor/crest or.pdf. Accessed 11 Apr 2019.

93. Merck Sharp \& Dohme Corp. MEVACOR (lovastatin) prescribing information. 2012. https://www.accessdata.fda.gov/drugs atfda_docs/label/2012/019643s085lbl.pdf. Accessed 11 Apr 2019.

94. Novartis Pharmaceuticals Corporation. Lescol ${ }^{\circledR}$ (fluvastatin sodium) prescribing information. 2017. https://www.pharm a.us.novartis.com/sites/www.pharma.us.novartis.com/files/Lesco 1.pdf. Accessed 11 Apr 2019.

95. Prueksaritanont T, Chu X, Evers R, Klopfer SO, Caro L, Kothare $\mathrm{PA}$, et al. Pitavastatin is a more sensitive and selective organic anion-transporting polypeptide $1 \mathrm{~B}$ clinical probe than rosuvastatin. Br J Clin Pharmacol. 2014;78:587-98.

96. Kowa Pharmaceuticals America Inc. LIVALO ${ }^{\circledR}$ (pitavastatin) prescribing information. 2016. https://www.kowapharma.com/ documents/LIVALO_PI_CURRENT.pdf. Accessed 11 Apr 2019.

97. Centers for Disease Control and Prevention (CDC). HIV Surveillance Report-Diagnoses of HIV Infection in the United States and Dependent Areas, 2016. 2016. https://www.cdc.gov/hiv/pdf/ library/reports/surveillance/cdc-hiv-surveillance-report-2016vol-28.pdf. Accessed 23 Jan 2019.

98. Mimiaga MJ, Reisner SL, Grasso C, Crane HM, Safren SA, Kitahata MM, et al. Substance use among HIV-infected patients engaged in primary care in the United States: findings from the Centers for AIDS Research Network of Integrated Clinical Systems cohort. Am J Public Health. 2013;103:1457-67.

99. American Society of Addiction Medicine (ASAM). The ASAM national practice guideline for the use of medications in the treatment of addiction involving opioid use. 2015. https://www.asam. org/docs/default-source/practice-support/guidelines-and-conse nsus-docs/asam-national-practice-guideline-supplement.pdf. Accessed 23 Jan 2019.
100. Stein MD, Urdaneta ME, Clarke J, Maksad J, Sobota M, Hanna $\mathrm{L}$, et al. Use of antiretroviral therapies by HIV-infected persons receiving methadone maintenance. J Addict Dis. 2000;19:85-94.

101. Indivior Inc. SUBOXONE ${ }^{\circledR}$ (buprenorphine and naloxone) prescribing information. 2018. https://www.suboxone.com/content/ pdfs/prescribing-information.pdf. Accessed 24 October 2018.

102. Teva Pharmaceuticals. NORDETTE ${ }^{\circledR}-28$ prescribing information. 2012. https://www.accessdata.fda.gov/drugsatfda_docs/ label/2013/018782s036lbl.pdf. Accessed 24 May 2019.

103. Wang B, Sanchez RI, Franklin RB, Evans DC, Huskey SE. The involvement of CYP3A4 and CYP2C9 in the metabolism of 17 $\alpha$-ethinylestradiol. Drug Metab Dispos. 2004;32:1209-12.

104. Moreno I, Quinones L, Catalan J, Miranda C, Roco A, Sasso $\mathrm{J}$, et al. Influence of CYP3A4/5 polymorphisms in the pharmacokinetics of levonorgestrel: a pilot study. Biomedica. 2012;32:570-7.

105. van Lunzen J, Liess H, Arastéh K, Walli R, Daut B, Schürmann D. Concomitant use of gastric acid-reducing agents is frequent among HIV-1-infected patients receiving protease inhibitor-based highly active antiretroviral therapy. HIV Med. 2007;8:220-5.

106. Wilby KJ, Elssa NA. Clinical pharmacokinetics and drug interactions of doravirine. Eur J Drug Metab Pharmacokinet. 2018:43:637-44.

107. Boyle A, Moss CE, Marzolini C, Khoo S. Clinical pharmacodynamics, pharmacokinetics, and drug interaction profile of doravirine. Clin Pharmacokinet. 2019;58:1553-65.

108. Taburet AM, Piketty C, Chazallon C, Vincent I, Gerard L, Calvez $\mathrm{V}$, et al. Interactions between atazanavir-ritonavir and tenofovir in heavily pretreated human immunodeficiency virus-infected patients. Antimicrob Agents Chemother. 2004;48:2091-6. 